NBSIR 88-3734

Estimating the Environment and the Response of Sprinkler Links in Compartment Fires with Draft Curtains and Fusible Link-Actuated Ceiling Vents Part I: Theory

Leonard $\mathrm{Y}$. Cooper

U.S. DEPARTMENT OF COMMERCE

National Bureau of Standards

National Engineering Laboratory

Center for Fire Research

Gaithersburg, MD 20899

April 1988

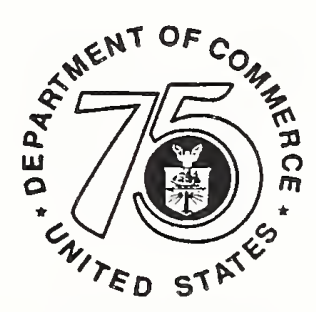

Sponsored by:

75 Youtr Stimuluting Amorics is Progrese

AAMA Research Foundation

2700 River Road, Suite 118

Des Plaines, lllinois 60018 
ESTIMATING THE ENVIRONMENT

AND THE RESPONSE OF SPRINKLER

LINKS IN COMPARTMENT FIRES WITH

DRAFT CURTAINS AND FUSIBLE

LINK- ACTUATED CEILING VENTS -

PART I: THEORY

Leonard Y. Cooper

U.S. DEPARTMENT OF COMMERCE

National Bureau of Standards

National Engineering Laboratory

Center for Fire Research

Gaithersburg, MD 20899

April 1988

Sponsored by:

AAMA Research Foundation

2700 River Road, Suite 118

Des Plaines, Illinois 60018

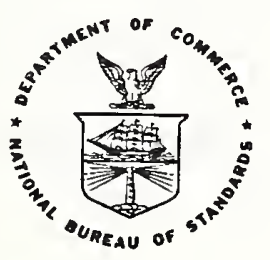

U.S. DEPARTMENT OF COMMERCE, C. William Verity, Secretary NATIONAL BUREAU OF STANDARDS, Ernest Ambler, Director 
1. Introduction . . . . . . . . . . . . . . . . . . . . . . . . 2

2. The Basic Equations . . . . . . . . . . . . . . . . . . . . . . . . . 2

3. Mass Flow and Enthalpy Flow Plus Heat Transfer... . . . . . . . . . . 5

3.1. Flow to the Upper Layer from the Vents . . . . . . . . . . . . 5

3.2. Flow to the Layer from the Plume and Radiation from the Fire . 5

3.3. Flow to the Layer from Below the Curtains . . . . . . . . . . 7

3.4. Heat Transfer to the Upper Layer . . . . . . . . . . . . . . . 8

3.4.1. Properties of the Plume in the Upper Layer When

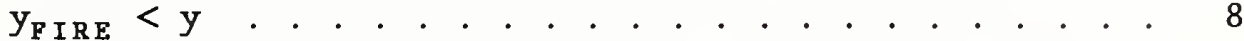

3.4.2. General Properties of the Plume in the Upper Layer . . 11

3.4.3. Computing $\mathrm{q}_{\mathrm{B} \mathrm{T}}$ and the Thermal Response of the Ceiling . . . . . . . . . . . . . . . . . . . . . . . 11

3.4.3.1. Net Heat Transfer Flux to the Ceiling's Lower Surface . . . . . . . . . . . . . 13

3.4.3.2. Net Heat Transfer Flux to Ceiling's Upper Surface .. . . . . . . . . . . . . . . 14

3.4.3.3. Solving for the Thermal Response of the Ceiling and for $\mathrm{q}_{\mathrm{B}} \mathrm{T}$

4. Actuation of Vents and Sprinklers by Near-Ceiling-Deployed Fusible

Links

4.1 Predicting the Thermal Response of the Fusible Links . . . . . 16

4.2 The Velocity Distribution of the Ceiling Jet . . . . . . . . . 17

4.3 The Temperature Distribution of the Ceiling Jet . . . . . . . . 18

4.4 Dependence of Open Vent Area on Fusible Link-Actuated Vents . . 20

5. Initiating the Solution of the Model Equations . . . . . . . . . . . . 21

6. Concluding Remarks . . . . . . . . . . . . . . . . . . . . . . . . . 22

7. Acknowledgements . . . . . . . . . . . . . . . . . . . . . 22

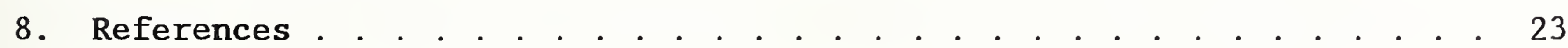

9. Nomenclature . . . . . . . . . . . . . . . . . . . . 25 


\section{LIST OF FIGURES}

Page

Figure 1. Fire in a building space with draft curtains and ceiling vents

Figure 2. The fire and the equivalent source in the lower layer and the continuation source in the extended upper layer . . . . . .

Figure 3. A plot of dimensionless ceiling jet velocity distribution, $\mathrm{V}_{\mathrm{CJ}} / \mathrm{V}_{\mathrm{MAX}}$, as a function of $\mathrm{z} /(0.23 \delta)$ per Eq. (49) . . . .

Figure 4. Plots of dimensionless ceiling jet temperature distribution, 8 , as a function of $z /(0.23 \delta)$ per Eq. (52) for cases when $\theta_{S}$ is $<0$, between 0 and 1 , and $>0 . . . . . . . . . .$. 


\title{
ESTIMATING THE ENVIRONMENT AND THE RESPONSE OF SPRINKLER LINKS IN COMPARTMENT FIRES WITH DRAFT CURTAINS AND FUSIBLE LINK-ACTUATED CEILING VENTS - PART I: THEORY
}

Leonard Y. Cooper

\begin{abstract}
The physical basis and associated mathematical model for estimating the firegenerated environment and the response of sprinkler links in well-ventilated compartment fires with draft curtains and fusible link-actuated ceiling vents is developed. Complete equations and assumptions are presented. Phenomena taken into account include: the flow dynamics of the upward-driven, buoyant fire plume; growth of the elevated-temperature smoke layer in the curtained compartment; the flow of smoke from the layer to the outside though open ceiling vents; the flow of smoke below curtain partitions to building spaces adjacent to the curtained space of fire origin; continuation of the fire plume in the upper layer; heat transfer to the ceiling surface and the thermal response of the ceiling as a function of radial distance from the point of plume-ceiling impingement; the velocity and temperature distribution of plumedriven near-ceiling flows and the response of near-ceiling-deployed fusible links as functions of distance below the ceiling and distance from plumeceiling impingement.

The theory presented here is the basis of a computer model now under development which will be used to study parametrically a wide range of relevant fire scenarios. The results of the parametric study will be presented in the Part II: Applications portion of this paper.
\end{abstract}

Keywords: algorithms; building fires; compartment fires; computer models; fire models; mathematical models; vents; sprinkler response; zone models. 


\section{Introduction}

Consider a space of plan area A defined by ceiling-mounted draft curtains with a fire of time-dependent energy release rate $Q(t)>0$ and with open ceiling vents of total time-dependent area $A_{V}(t)$. The curtained area can be considered as one of several such spaces in a large building compartment. Also, by specifying the curtains to be deep enough they can be thought of as simulating the walls of a single uncurtained compartment. This paper presents the physical basis and associated mathematical model for estimating the firegenerated environment and the response of sprinkler links in curtained compartment fires with fusible link-actuated ceiling vents. The problem addressed in this work is similar to the problem addressed in [1]. The theory presented here is the basis of a computer model which will be developed and then used to study parametrically a wide range of relevant fire scenarios. The results of the parametric study will be presented in the Part II: Applications portion of this paper [2].

The overall building compartment is assumed to have near-floor wall vents which are large enough to maintain the inside environment, below any near ceiling smoke layers which may form, at assumed initial outside-ambient conditions. Figure 1 depicts the generic fire scenario of interest. The assumption of large near-floor wall vents will require that the modeling be restricted to conditions where $y$, the elevation of the smoke layer interface, is above the floor elevation, i.e., $y>0$. The assumption also has important implications with regard to the cross-ceiling vent pressure differential. This is the pressure differential which drives elevated-temperature upper layer smoke through the ceiling vents to the outside. Thus, below the smoke layer (i.e., from the floor of the facility to the elevation of the smoke layer interface) the inside-to-outside hydrostatic pressure differential will be zero, while a positive inside-to-outside pressure differential will exist at all elevations in the reduced-density smoke layer itself (higher pressure inside the curtained area, lower pressure in the outside environment), the maximum differential occurring at the ceiling and across the open ceiling vents.

\section{The Basic Equations}

A two-layer zone-type compartment fire model is used to describe the phenomena under investigation and, as is typical in such models, the upper smoke layer is assumed to be uniform in density, $\rho_{U}$, and absolute temperature, $\mathrm{T}_{\mathrm{U}}$. The following time-dependent equations describe conservation of energy, mass and the perfect gas law in the upper smoke layer

Conservation of Energy:

$$
\mathrm{d}\left[\left(\mathrm{y}_{\mathrm{CEIL}}-\mathrm{y}\right) \rho_{\mathrm{U}} \mathrm{T}_{\mathrm{U}} \mathrm{AC} \mathrm{v}\right] / \mathrm{dt}=\mathrm{q}_{\mathrm{U}}+\mathrm{pAdy} / \mathrm{dt}
$$


Conservation of Mass:

$$
\mathrm{d}\left[\left(\mathrm{y}_{\mathrm{CEIL}}-\mathrm{y}\right) \rho_{\mathrm{U}} \mathrm{A}\right] / \mathrm{dt}=\mathrm{m}_{\mathrm{U}}
$$

Perfect Gas Law:

$$
\mathrm{P}_{U} / \mathrm{R} \simeq \mathrm{p} / \mathrm{R}=\text { constant }=\rho_{\mathrm{U}} \mathrm{T}_{\mathrm{U}}=\rho_{\mathrm{AMB}} \mathrm{T}_{\mathrm{AMB}} \text {, i.e., } \mathrm{T}_{U}=\mathrm{T}_{\mathrm{AMB}}\left(\rho_{\mathrm{AMB}} / \rho_{\mathrm{U}}\right)
$$

where $y_{C E I L}$ is the elevation of the ceiling above the floor, $R=C_{p}-C_{v}$ is the gas constant, $C_{p}$ and $C_{v}$ are the specific heats at constant pressure and volume, respectively, and $\mathrm{p}$ is a constant characteristic pressure, say, $\mathrm{p}_{\mathrm{ATM}}$ at the floor elevation. In Eq. (1) $\mathrm{q}_{U}$ is the net rate of enthalpy flow plus heat transfer to the upper layer and is made up of flow components: $q_{C U R T}$, from below the curtain, $q_{P L U M E}$, from the plume, $q_{V E N T}$, from the ceiling vent; and the component $\mathrm{q}_{\mathrm{HT}}$, the total heat transfer rate

$$
\mathrm{q}_{U}=\mathrm{q}_{\mathrm{CURT}}+\mathrm{q}_{\mathrm{PLUME}}+\mathrm{q}_{\mathrm{VENT}}+\mathrm{q}_{\mathrm{HT}}
$$

In Eq. (2) $m_{U}$ is the net rate of mass flow to the upper layer with flow components: $m_{C U R T}$, from below the curtain, $m_{P L U M E}$, from the plume, and $m_{V E N T}$, from the ceiling vent

$$
m_{U}=m_{C U R T}+m_{P L U M E}+m_{V E N T}
$$

Using Eq. (3) in Eq. (1) leads to

$$
\begin{aligned}
& \mathrm{dy} / \mathrm{dt}=-\mathrm{q}_{U} /\left(\mathrm{AC}_{\mathrm{p}} \rho_{\mathrm{AMB}} \mathrm{T}_{\mathrm{AMB}}\right) \\
& \text { if }\left(\mathrm{y}=\mathrm{y}_{\mathrm{CEIL}} \text { and } \mathrm{q}_{U} \geq 0\right) \text { or }\left(0<\mathrm{y}<\mathrm{y}_{\mathrm{CEIL}} \text { and arbitrary } \mathrm{q}_{U}\right)
\end{aligned}
$$

The first of these conditions will be seen below to be consistent with our earlier, $\mathrm{Q}>0$ assumption. In particular, we will see that $\mathrm{q}_{U}>0$ initially when $\mathrm{y}=\mathrm{y}_{\mathrm{CEIL}}$. Therefore, Eq. (6) will always be applicable.

Using Eq.(1), Eq. (2) can be rewritten as

$$
\mathrm{d} \rho_{\mathrm{U}} / \mathrm{dt}=\left(\mathrm{m}_{\mathrm{U}}+\rho_{\mathrm{U}} \mathrm{Ady} / \mathrm{dt}\right) /\left[\left(\mathrm{y}_{\mathrm{CEIL}}-\mathrm{y}\right) \mathrm{A}\right] \text { if } 0<\mathrm{y}<\mathrm{y}_{\mathrm{CEIL}}
$$


Since the denominator of Eq. (7) is zero at the initiation of a fire (i.e., when $\left.\mathrm{y}=\mathrm{y}_{\mathrm{CEIL}}\right), \mathrm{d} \rho_{\mathrm{U}} / \mathrm{dt}$ is indeterminant at that time. However, as mentionedabove, in our $\mathrm{Q}>0$ scenarios $\mathrm{q}_{U}>0$ generally at $t=0$ and for this reason a nonzero, initial dy/dt value is predicted by Eq. (6). Then, since d $\rho_{\mathrm{U}} / \mathrm{d} t$ of Eq. (7) is expected to exist for $t>0$ it is reasonable to require the numerator of Eq. (7) to be zero at $t=0$, thereby obtaining the initial value of $\rho_{U}$. Doing this leads to

$$
\rho_{U}(t=0)=\rho_{A M B} T_{A M B} C_{p} m_{U} / q_{U}
$$

The above value for $\rho_{\mathrm{U}}(t=0)$ can be shown to be identical to the initial average density of the plume flow at the elevation of ceiling impingement after all heat transfer from the plume-flow-driven ceiling and wall jets have been taken into account.

Solving for $\rho_{\mathrm{U}}$ requires a definite value for $\mathrm{d} \rho_{\mathrm{U}} / \mathrm{dt}$ at $t=0$, i.e., at $\mathrm{y}=\mathrm{y}_{\mathrm{CEIL}}$, which is not provided in Eq. (7). To obtain the correct value for this requires the results of a detailed analysis of the limiting small-t values of $\mathrm{m}_{U}, \mathrm{dm}_{\mathrm{U}} / \mathrm{dt}, \mathrm{q}_{\mathrm{U}}$, and $\mathrm{dq}_{U} / \mathrm{dt}$. Such an analysis can only be carried out within the context of a specific plume model. To avoid this problem, we will take arbitrarily the value of $\mathrm{d} \rho_{\mathrm{U}} / \mathrm{d} t$ to be zero at $t=0$. Thus, Eq. (7) becomes

$$
\mathrm{d} \rho_{\mathrm{U}} / \mathrm{d} t=\left\{\begin{array}{l}
\left(\mathrm{m}_{\mathrm{U}}+\rho_{\mathrm{U}} \mathrm{Ady} / \mathrm{d} t\right) /\left[\left(\mathrm{y}_{\mathrm{CEIL}}-\mathrm{y}\right) \mathrm{A}\right] \text { if } 0<\mathrm{y}<\mathrm{y}_{\mathrm{CEII}} \\
0 \text { if } t=0, \text { i.e., when } \mathrm{y}=\mathrm{y}_{\mathrm{CEIL}}
\end{array}\right.
$$

it is expected that by using a robust numerical integrator and relatively tight tolerances to solve the governing Eqs. (6) and ( $7^{\prime}$ ) the solution for $\rho_{U}$ will recover quickly from an incorrect initial value for $\mathrm{d} \rho_{\mathrm{U}} / \mathrm{d} t$ and the correct solution for $\rho_{U}$ will still be obtained for $t>0$.

The basic problem of simulating mathematically the growth and properties of the upper layer for the generic Figure 1 scenario will require the solution of the system of Eqs. (6) and ( $7^{\prime}$ ) for $y$ and $\rho_{U}$. Using the computed values of $\rho_{U}$ at any instant of time, the subsidiary Eq. (3) can then be used to solve for $\mathrm{T}_{\mathrm{U}}$. To integrate Eqs. (6) and ( $7^{\prime}$ ) requires algorithms for calculating the various components of $\mathrm{q}_{U}$ and $\mathrm{m}_{U}$ indicated in Eqs. (4) and (5). These will be obtained below. 


\section{Mass Flow and Enthalpy Flow Plus Heat Transfer}

\subsection{Flow to the Upper Layer from the Vents}

Conservation of momentum across all open ceiling vents as expressed by Bernoulli's equation leads to

$$
\begin{aligned}
& \mathrm{V}=\mathrm{C}\left(2 \Delta \mathrm{p}_{\mathrm{CEIL}} / \rho_{\mathrm{U}}\right)^{1 / 2} \\
& \mathrm{~m}_{\mathrm{VENT}}=-\rho_{\mathrm{U}} \mathrm{A}_{\mathrm{V}} \mathrm{V}=-\mathrm{A}_{\mathrm{V}} \mathrm{C}\left(2 \rho_{\mathrm{U}} \Delta \mathrm{p}_{\mathrm{CEIL}}\right)^{1 / 2}
\end{aligned}
$$

where $\mathrm{V}$ is the average velocity through all open vents, $\mathrm{C}$ is the vent flow coefficient $(\approx 0.68[3])$, and $\Delta \mathrm{P}_{\mathrm{CEIL}}$ is the cross-vent pressure difference.

From hydrostatics

$$
\Delta \mathrm{p}_{\mathrm{CEIL}} \equiv \mathrm{p}_{U}\left(\mathrm{y}=\mathrm{y}_{\mathrm{CEIL}}\right)-\mathrm{p}_{\mathrm{AMB}}\left(\mathrm{y}=\mathrm{y}_{\mathrm{CEIL}}\right)=\left(\rho_{\mathrm{AMB}}-\rho_{\mathrm{U}}\right) \mathrm{g}\left(\mathrm{y}_{\mathrm{CEIL}}-\mathrm{y}\right)
$$

where $g$ is the acceleration of gravity.

Substituting Eq. (11) in Eq. (10) leads to the desired result for $\mathrm{m}_{\mathrm{VENT}}$

$$
\mathrm{m}_{\mathrm{VENT}}=-\mathrm{A}_{\mathrm{V}} \mathrm{C}\left[2 \rho_{\mathrm{U}}\left(\rho_{\mathrm{AMB}}-\rho_{\mathrm{U}}\right) \mathrm{g}\left(\mathrm{y}_{\mathrm{CEIL}}-\mathrm{y}\right)\right]^{1 / 2}
$$

which is equivalent to the equations used to estimate ceiling vent flow rates in [4] and [5]. Using Eq. (12) we can obtain the desired result for qVEN

$$
\mathrm{q}_{V E N T}=\mathrm{m}_{\mathrm{VENT}} \mathrm{C}_{\mathrm{p}} \mathrm{T}_{\mathrm{U}}
$$

\subsection{Flow to the Layer from the Plume and Radiation from the Fire}

It is assumed that the mass generation rate of the fire is small compared to $\mathrm{m}_{\mathrm{ENT}}$, the rate of mass of air entrained into the plume between the fire elevation, $y_{F I R E}$, and the layer interface, or compared to other mass flow rate components of $\mathrm{m}_{U}$. It is also assumed that all of the $\mathrm{m}_{E N T}$ penetrates the layer interface and enters the upper layer. Thus 
and

$$
\mathrm{q}_{\mathrm{PLUME}}=\mathrm{m}_{\mathrm{ENT}} \mathrm{C}_{\mathrm{p}} \mathrm{T}_{\mathrm{AMB}}+\left(1-\lambda_{\mathrm{r}}\right) \mathrm{Q}
$$

The first term on the right side of Eq. (15) is the enthalpy associated with $\mathrm{m}_{E N T}$ and $\lambda_{r}$ of the second term is the effective fraction of $\mathrm{Q}$ assumed to be radiated isotropically from the fire's combustion zone.

It is assumed that the smoke layer is relatively transparent and that it does not participate in any significant radiation heat transfer exchanges. In particular, all of the $\lambda_{r} Q$ radiation is assumed to be incident on the bounding surfaces of the compartment. Thus, the last term of Eq. (15) is the net amount of enthalpy added to the upper layer from the combustion zone and its buoyantly-driven plume. Flaming fires exhibit $\lambda_{\mathrm{r}}{ }^{\prime} \mathrm{s}$ of $0<\lambda_{\mathrm{r}}<0.6$, e.g., smaller values for small methane fires and the higher values for large polystyrene fires. However, for a hazardous fires involving a wide range of common groupings of combustibles, it is reasonable to approximate flame radiation by choosing $\lambda_{r} \simeq 0.35[6]$.

A specific plume entrainment model is required to complete Eqs. (14)-(15) for $m_{P L U M E}$ and $q_{P L U M E}$. The following estimate for $m_{E N T}$, developed in [7] and discussed in [8] will be adopted here

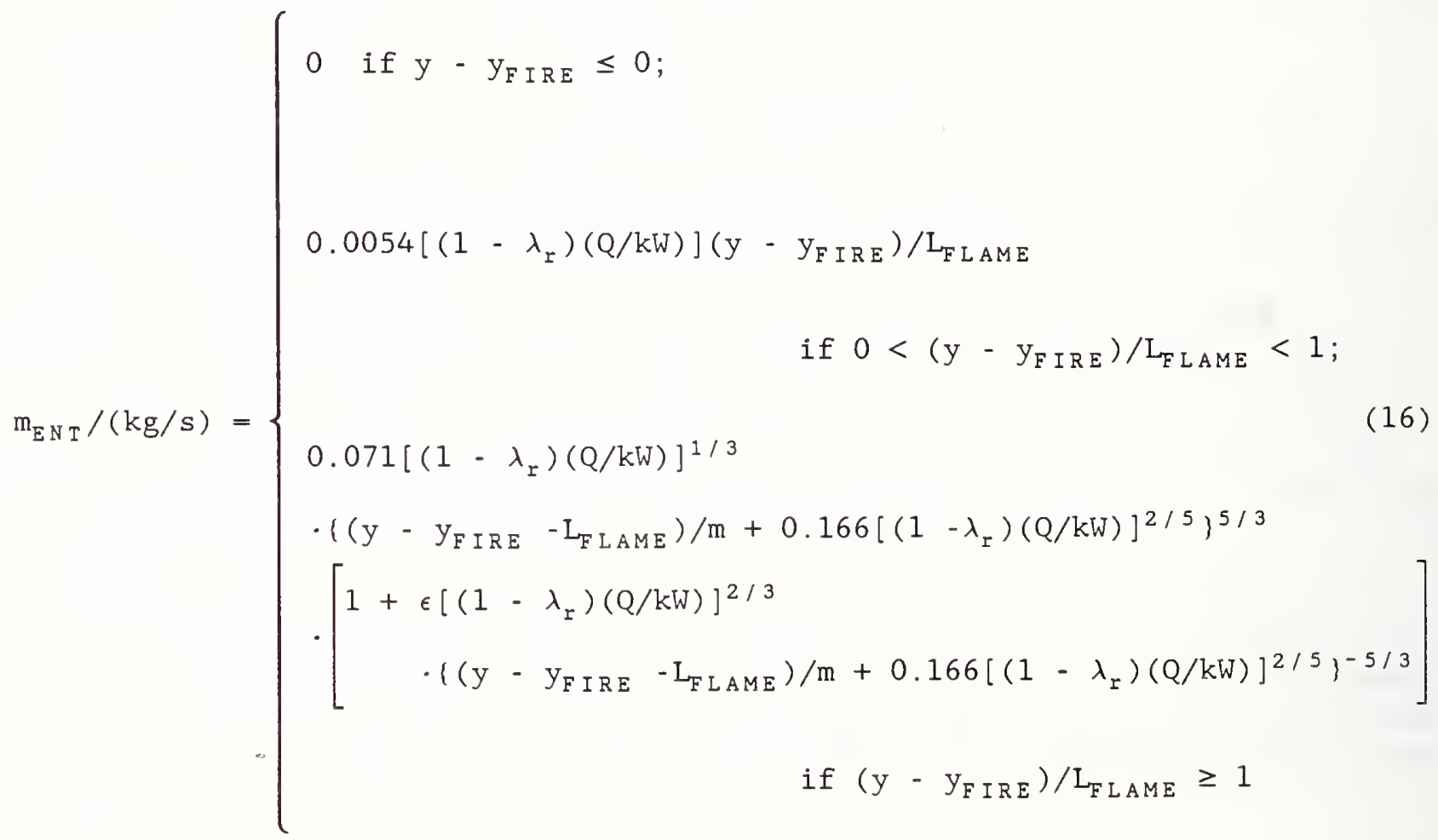




$$
\begin{aligned}
& L_{\text {FLAME }} / D_{\text {FIRE }}=-1.02+0.249\left[\left(1-\lambda_{\mathrm{r}}\right)(\mathrm{Q} / \mathrm{kW})\right]^{2 / 5} /\left(\mathrm{D}_{\text {FIRE }} / \mathrm{m}\right) \\
& \epsilon=0.0054 / 0.071-(0.166)^{5 / 3}=0.0259168209 \ldots \simeq 0.026
\end{aligned}
$$

where $I_{F L A M E}$ is the fire's flame length, $D_{F I R E}$ is the effective diameter of the fire source $\left(\pi D_{F I R E}^{2} / 4=\right.$ area of the fire source), and $\epsilon$ is chosen so that, analytically, the value of $\mathrm{m}_{E N \mathrm{~T}}$ is exactly continuous at the elevation $y-y_{\text {FIRE }}=L_{\text {FLAME }}$.

\subsection{Flow to the Layer from Below the Curtains}

If the upper layer interface, $y$, drops below the elevation of the bottom of the curtains, $y_{C U R T}$, then there will be mass and enthalpy flows from the upper layer of the curtained area where the fire is located to adjacent curtained areas of the overall building compartment. The mass flow rate will be the result of hydrostatic cross-curtain pressure differentials. Provided adjacent curtained areas are not yet filled with smoke, this pressure differences increases linearly from zero at the layer interface to $\Delta \mathrm{p}_{\mathrm{CURT}}$ at $\mathrm{y}=\mathrm{y}_{\mathrm{CURT}}$. From hydrostatics

$$
\Delta \mathrm{P}_{\mathrm{CURT}} \equiv \mathrm{p}_{U}\left(\mathrm{y}=\mathrm{y}_{\mathrm{CURT}}\right)-\mathrm{p}_{\mathrm{AMB}}\left(\mathrm{y}=\mathrm{y}_{\mathrm{CURT}}\right)=\left(\rho_{\mathrm{AMB}}-\rho_{U}\right) \mathrm{g}\left(\mathrm{y}_{\mathrm{CURT}}-\mathrm{y}\right)
$$

Using Eq. (19) together with well-known vent flow relations (e.g., Eq. (31) of [3]) $m_{C U R T}$ and the $q_{C U R T}$ can be estimated from

$$
\begin{aligned}
& \mathrm{m}_{\mathrm{CURT}}=\left\{\begin{array}{l}
0 \quad \text { if } \mathrm{y} \geq \mathrm{y}_{\mathrm{CURT}} \\
-\left(\mathrm{L}_{\mathrm{CURT}} / 3\right)\left[8\left(\mathrm{y}_{\mathrm{CURT}}-\mathrm{y}\right)^{3} \rho_{\mathrm{U}}\left(\rho_{\mathrm{AMB}}-\rho_{\mathrm{U}}\right) \mathrm{g}\right]^{1 / 2} \text { if } \mathrm{y} \leq \mathrm{y}_{\mathrm{CURT}}
\end{array}\right. \\
& \mathrm{q}_{\mathrm{CURT}}=\mathrm{m}_{\mathrm{CURT}} \mathrm{C}_{\mathrm{p}} \mathrm{T}_{\mathrm{U}}
\end{aligned}
$$

where $L_{C U R T}$ is that length of the perimeter of area $A$ which is connected to other curtained areas of the overall building compartment. For example, if the curtained area is in one corner of the building compartment, then the length of its two sides coincident with the walls of the compartment will not be included in $L_{C U R T}$. Since the generic vent flow configuration under consideration here is very long and narrow, a flow coefficient for the vent flow used in Eq. (20) was taken to be 1 . 


\subsection{Heat Transfer to the Upper Layer}

As discussed above in section 3.2., when the fire is below the layer interface the buoyant fire plume rises toward the ceiling and all of its mass and enthalpy flow, $m_{P L U M E}$ and $q_{P L U M E}$, is assumed to be deposited into the upper layer. Having penetrated the interface, the plume continues to rise toward the ceiling of the curtained compartment. As it impinges on the ceiling surface, the plume flow turns and forms a relatively high temperature, high velocity, turbulent ceiling jet which flows radially outward along the ceiling and transfers heat to the relatively cool ceiling surface. The ceiling jet is cooled by convection and the ceiling material is heated indepth by conduction. The convective heat transfer rate is a strong function of the radial distance from the point of plume/ceiling impingement, reducing rapidly with increasing radius. It is dependent also on the characteristics of the plume immediately upstream of ceiling impingement.

The ceiling jet is blocked eventually by the curtains and/or wall surfaces. It then turns downward and forms vertical surface flows. In the case of wall surfaces and very deep curtains, the descent of these flows is stopped eventually by upward buoyant forces and they mix finally with the upper layer. Here we assume that the plume/ceiling impingement point is relatively far from the closest curtain or wall surface, say, greater than a few.fire-to-ceiling lengths. Under such circumstances the ceiling jet - wall flow interactions will be relatively weak and, compared to the net rate of heat transfer from the ceiling and near the plume/ceiling impingement point, the heat transfer to the upper layer from all vertical surfaces will be relatively small.

Define $\lambda_{\text {CONV }}$ as the fraction of $Q$ which is transferred by convection from the upper layer gas ceiling jet to the ceiling and wall/curtain surfaces

$$
\mathrm{q}_{\mathrm{HI}}=-\lambda_{\mathrm{CONV}} \mathrm{Q}
$$

Once the values of $\lambda_{\mathrm{CONV}} \mathrm{Q}$ and $\mathrm{q}_{\mathrm{HT}}$ are determined from a time-dependent solution to the coupled, ceiling jet/ceiling material, convection/conduction problem the task of determining an estimate for each component of $m_{V}$ and $q_{U}$ will be complete.

\subsubsection{Properties of the Plume in the Upper Layer When $\mathrm{y}_{F I R E}<\mathrm{y}$}

Consider times when the elevation of the fire is below the interface, i.e., when $\mathrm{y}_{F \text { IRE }}<\mathrm{y}$.

As the plume flow enters the upper layer the forces of buoyancy which act to drive the plume toward the ceiling (i.e., as a result of relatively hightemperature, low-density plume gases being submerged in a relatively cool, high-density ambient environment) are reduced immediately because of the temperature increase of the upper layer environment over that of the lower 
ambient. As a result, the continued ascent of the plume gases will be less vigorous, i.e., at reduced velocity, and of higher temperature than it would have been in the absence of the layer. Indeed, some of the penetrating plume flow, will actually be at a lower temperature than $\mathrm{T}_{\mathrm{U}}$. The upper layer buoyant forces on this latter portion of the flow will actually retard and possibly stop its subsequent rise to the ceiling.

The simple point source plume model of [9] will be used to simulate the plume flow, first immediately below, or upstream of the interface, and then throughout the depth of the upper layer itself.

The plume above a Reference-[9]-type point source of buoyancy, where the source is below the interface, will be equivalent to the plume of our fire (in the sense of having identical mass and enthalpy flow rates at the interface) if the point source strength is $\left(1-\lambda_{r}\right) Q$ and the elevation of the equivalent source, $\mathrm{Y}_{E Q}$, satisfies

$$
\mathrm{m}_{\mathrm{PL} U \mathrm{ME}}=0.21 \rho_{\mathrm{AMB}} \mathrm{g}^{1 / 2}\left(\mathrm{y}-\mathrm{y}_{\mathrm{EQ}}\right)^{5 / 2} \mathrm{Q}_{\mathrm{EQ}}^{*}{ }^{1 / 3}
$$

In the above, $\mathrm{Q}_{\mathrm{EQ}}^{*}$, a dimensionless measure of the strength of the fire plume at the interface, is defined as

$$
\mathrm{Q}_{\mathrm{EQ}}^{*}=\left(1-\lambda_{\mathrm{r}}\right) \mathrm{Q} /\left[\rho_{\mathrm{AMB}} \mathrm{C}_{\mathrm{p}} \mathrm{T}_{\mathrm{AMB}} \mathrm{g}^{1 / 2}\left(\mathrm{y}-\mathrm{y}_{\mathrm{EQ}}\right)^{5 / 2}\right]
$$

Note that at an arbitrary instant of time in the simulation of a fire scenario, $\mathrm{m}_{\mathrm{PLUME}}$ in Eq. (23) is a known value that would be determined previously from Eqs. (14) and (16).

Using (23) and (24) we solve for $y_{E Q}$ and $Q_{E Q}^{*}$

$$
\begin{aligned}
& y_{E Q}=y-\left[\left(1-\lambda_{r}{ }^{*}\right) Q /\left(Q_{E Q}^{*} \rho_{A M B} C_{p} T_{A M B} g^{1 / 2}\right)\right]^{2 / 5} \\
& Q_{E Q}^{*}=\left[0.21\left(1-\lambda_{r}\right) Q /\left(C_{p} T_{A M B} m_{P L U M E}\right)\right]^{3 / 2}
\end{aligned}
$$

Now as the plume crosses the interface, the fraction, $\mathrm{m}^{*}$, of $\mathrm{m}_{\mathrm{PLUME}}$ which is still buoyant relative to the upper layer environment and presumably continues to rise to the ceiling, entraining upper layer gases along the way, is predicted in [10] to be

$$
\mathrm{m}^{*}=\left\{\begin{array}{l}
0 ;-1<\sigma \leq 0 \\
\left(1.04599 \sigma+0.360391 \sigma^{2}\right) /\left(1+1.37748 \sigma+0.360391 \sigma^{2}\right) ; \sigma>0
\end{array}\right.
$$


where the dimensionless parameter $\sigma$ is defined as

$$
\begin{gathered}
\sigma=\left(1-\alpha+\mathrm{C}_{\mathrm{T}} \mathrm{Q}_{\mathrm{EQ}}^{*} 2 / 3\right) /(\alpha-1) \\
\alpha=\mathrm{T}_{\mathrm{U}} / \mathrm{T}_{\mathrm{AMB}} ; \mathrm{C}_{\mathrm{T}}=9.115
\end{gathered}
$$

and where $Q_{E Q}^{*}$ is the value computed above in Eq. (26). Reference [10] identifies further the parameters necessary to describe plume flow continuation in the upper layer (i.e., between $y$ and $y_{C E I L}$ ) according to a Reference-[9]-type point source plume. It has been determined that this plume can be modeled as being driven by a non-radiating buoyant source of strength $Q^{\prime}$ located a distance

$$
H=y_{C E I L}-y_{\text {SOURCE }}^{\prime}>y_{C E I L}-y_{F I R E}
$$

below the ceiling in a (downward-) extended upper layer environment of temperature $\mathrm{T}_{U}$ and density $\rho_{U}$. The relevant parameters predicted in [10] are

$$
\begin{aligned}
& \mathrm{Q}^{\prime}=\left(1-\lambda_{\mathrm{I}}\right) \mathrm{Q} \sigma \mathrm{m}^{*} /(1+\sigma) \\
& \mathrm{y}_{\text {SOURCE }}^{\prime}=\mathrm{y}-\left(\mathrm{y}-\mathrm{y}_{\mathrm{EQ}}\right) \alpha^{3 / 5} \mathrm{~m}^{* 2 / 5}[(1+\sigma) / \sigma]^{1 / 5}
\end{aligned}
$$

The fire and the equivalent source in the lower layer and the continuation source in the upper layer are depicted in Figure 2. Times during a fire simulation when Eq. (28) predicts $\sigma \gg>1$ are related to states of the fire environment when the temperature distribution above $\mathrm{T}_{\mathrm{AMB}}$ of the plume flow, at the elevation of interface penetration, is predicted to be mostly much larger than $\left(\mathrm{T}_{U}-\mathrm{T}_{A M B}\right)$. Under such circumstances the penetrating plume flow is still very strongly buoyant as it enters the upper layer. The plume will continue to rise to the ceiling and to drive ceiling jet convective heat transfer at rates which differ only slightly (on account of the elevated temperature upper layer environment) from the heat transfer rates which could occur in the absence of an upper layer.

Conditions where Eq. (28) predicts $\sigma<0$ are related to times during a fire scenario when the temperature of the plume at the elevation of interface penetration is predicted to be uniformly less than $\mathrm{T}_{U}$. Under such circumstances the penetrating plume flow is nowhere positively (i.e., upward) buoyant as it enters the upper layer. Thus, while all of this flow is assumed to enter and mix with the upper layer, it is predicted above that none of it rises to the ceiling in a coherent plume, i.e., $Q^{\prime}=0$. For this reason, when $\sigma<0$ the existence of any significant ceiling jet flow is precluded along with significant convective heat transfer to the ceiling surface or to nearceiling-deployed fusible links. 
The above analysis assumes that $y_{F I R E}<y$. However, at the onset of the fire scenario $\mathrm{y}_{F I R E}<\mathrm{y}=\mathrm{y}_{\mathrm{CEIL}}$ and, since they depend on the unknown initial value of $\mathrm{T}_{\mathrm{U}}, \alpha, \sigma$ and $\mathrm{m}^{*}$ of Eqs. (27)-(29) are undefined. More critical, however, is the fact that an internally-consistent value for $\rho_{\mathrm{U}}$ is required, but not available, to initiate the solution to the governing equations. The solution to this problem will be addressed it the last section of this work. For now, we assume that we are dealing with $t>0$, when $T_{U}$ is well-known.

\subsubsection{General Properties of the Plume in the Upper Layer}

When the fire is below the interface, the results of Eqs. (31') and (32') allow us to describe the fire-driven plume dynamics in the upper layer according to the point source plume model of [9]. If the fire is at or above the interface, i.e., $y_{F I R E} \geq y$, then $m_{P L U M E}=0, q_{P L U M E}=\left(1-\lambda_{r}\right) Q$, and we continue to use the point source model to simulate the upper layer plume flow. All cases can be treated with the following final versions of Eqs. (31') and (32')

$$
\begin{aligned}
& Q^{\prime}=\left\{\begin{array}{l}
\left(1-\lambda_{\mathrm{r}}\right) \mathrm{Q} \sigma \mathrm{m}^{*} /(1+\sigma) \text { if } \mathrm{y}_{\mathrm{FIRE}}<\mathrm{y} ; \\
\left(1-\lambda_{\mathrm{I}}\right) \mathrm{Q} \text { if } \mathrm{y}_{\mathrm{FIRE}} \geq \mathrm{y}
\end{array}\right. \\
& \mathrm{y}_{\text {SOURCE }}^{\prime}=\left\{\begin{array}{l}
\mathrm{y}-\left(\mathrm{y}-\mathrm{y}_{\mathrm{FIRE}}\right) \alpha^{3 / 5} \mathrm{~m}^{* 2 / 5}[(1+\sigma) / \sigma]^{1 / 5} \text { if } \mathrm{y}_{\text {FIRE }}<\mathrm{y} ; \\
\mathrm{y}_{\text {FIRE }} \text { if } \mathrm{y}_{\text {FIRE }} \geq \mathrm{y}
\end{array}\right.
\end{aligned}
$$

where $\mathrm{m}^{*}, \sigma$, and $\alpha$ are calculated from Eqs. (25)-(29).

$Q^{\prime}$ and $y_{S O U R C E}^{\prime}$ of Eqs. ( $\left.31^{\prime}\right)$ and (32') are the strength and location of a source of buoyancy embedded in the extended upper layer environment. This source is equivalent to the actual fire in the sense that Q', $y_{S O U R C E}^{\prime}$, and the point source plume model of Reference [9] describe the dynamics of the fire plume once it enters into and passes upward through the upper layer to the ceiling. Such an upper-layer plume description is required and will be used below to predict ceiling jet-driven convective heat transfer to the ceiling surface and to vent- and sprinkler-actuating fusible links.

\subsubsection{Computing $\mathrm{q}_{\mathrm{B}} \mathrm{T}$ and the Thermal Response of the Ceiling}

When the fire is below the interface and the interface is below the ceiling we will use the method of [11] for calculating the heat transfer from the plumedriven ceiling jet to the ceiling and the thermal response of the ceiling. 
This method was developed to treat generic, confined-ceiling, room fire scenarios. As in [11] we will solve the confined ceiling problem by applying the unconfined ceiling heat transfer solution, developed in [12] and [13], and applied in [14], to the problem of an Eq. (31')-(32') equivalent upper layer source in an extended upper layer environment. When the fire is above the interface, the unconfined ceiling methodology applies directly.

To use the methods of [11]-[14] we consider an arbitrary instant of time during the course of fire development. We assume that the temperature distribution of the ceiling material, $T$, has been computed up to this time and is known as a function of distance, Z, measured upward from the bottom surface of the ceiling, and radial distance, $r$, measured from the constant point of plume-ceiling impingement. Then the equivalent, extended-upper-layer, unconfined-ceiling flow and heat transfer problem is depicted in Figure 2 . It involves the equivalent $Q^{\prime}$ heat source of Eq. (31') located a distance H below the ceiling surface in an extended ambient environment of density $\rho_{U}$ and absolute temperature $\mathrm{T}_{U}$, where $\mathrm{H}$ is found from Eqs. (30) and (32).

The objective here is to estimate the instantaneous convective heat transfer flux from the upper-layer gas to the lower ceiling surface, q"onv, $(r, t)$, and the net heat transfer fluxes to the upper and lower surface of the ceiling, $\mathrm{q}_{U}^{\prime \prime}(r, t)$ and $\mathrm{q}_{\mathrm{L}}^{\prime \prime}(r, t)$, respectively. With this information, the time-dependent solution for the indepth thermal response of the ceiling material can be advanced to subsequent times. Also, q"onv, L can be integrated over the lower ceiling surface to obtain the desired instantaneous value for $\mathrm{q}_{\mathrm{H}}$.

In view of assumptions in Section 3.3 on the relatively large distance of the fire from walls or curtains and on the relatively small contribution of heat transfer to these vertical surfaces, it is reasonable to carry out a somewhat simplified calculation for $\mathrm{q}_{\mathrm{BI}}$. Thus, $\mathrm{q}_{\mathrm{HI}}$ will be approximated by the integral of $\mathrm{q}_{C \mathrm{~N} V}, \mathrm{~L}$ over an effective circular ceiling area $\mathrm{A}_{\mathrm{EFF}}$ with diameter $D_{E F F}$, centered at the point of impingement.

$$
\mathrm{q}_{\mathrm{H} T}=-\lambda_{\mathrm{CONV}} \mathrm{Q}(\mathrm{t})=-\int_{\mathrm{A}} \mathrm{q}_{\mathrm{CONV}, \mathrm{L}}^{\prime \prime}(r, t) d A \approx-2 \pi \int_{0}^{\mathrm{D}_{\mathrm{EFF}}^{\prime \prime} / 2} \mathrm{CONV}, \mathrm{L}^{\prime}(r, t) r d r
$$

The value $A_{E F F}=\pi D_{E F F}^{2} / 4$ will be taken to be the actual area of the curtained space, A, plus the portion of the vertical curtain and wall surfaces estimated to be covered by ceiling jet-driven wall flows. An estimate for this extended, effective ceiling surface area is obtained in [15] where it is concluded with some generality that ceiling jet-driven wall flows will penetrate a distance of approximately $0.8 \mathrm{H}$ down from the ceiling. Thus

$$
A_{E F F}=\pi D_{E F F}^{2} / 4=A+0.8 H\left(P-L_{C U R T}\right)+L_{C U R T} \min \left[0.8 H,\left(y_{C E I L}-y_{C U R T}\right)\right]
$$

where $P$ is the total length of the perimeter of the curtained area. 


\subsubsection{Net Heat Transfer Flux to the Ceiling's Lower Surface}

The net heat transfer flux to the ceiling's lower surface, $q_{L}^{\prime \prime}$, is made up of three components, incident radiation, $\mathrm{q}_{\mathrm{RAD}-\mathrm{FIRE}}$, convection, $\mathrm{q}_{\mathrm{CON}, \mathrm{L}}$, and reradiation, $\mathrm{q}_{\mathrm{RERAD}, \mathrm{L}}^{\prime \prime}$

$$
\mathrm{q}_{\mathrm{L}}^{\prime \prime}=\mathrm{q}_{\mathrm{RAD}-\mathrm{FIRE}}^{\prime}+\mathrm{q}_{\mathrm{CON}, \mathrm{L}}^{\prime \prime}+\mathrm{q}_{\mathrm{RERAD}, \mathrm{L}}^{\prime \prime}
$$

As discussed below in Section 3.2 the radiant energy from the fire, $\lambda_{r} Q$, is assumed to be radiated isotropically from the fire with negligible radiation absorption and emission from the compartment gases. Therefore

$$
q_{R A D-F I R E}^{\prime \prime}=\left\{\lambda_{r} Q /\left[4 \pi\left(y_{C E I L}-y_{F I R E}\right)^{2}\right]\right\}\left\{1+\left[r /\left(y_{C E I L}-y_{F I R E}\right)\right]^{2}\right\}^{-3 / 2}
$$

The convective heat transfer flux from-the upper-layer gas to the ceiling's lower surface can be calculated from $[12,13]$

$$
\mathrm{q}_{\mathrm{CONV}, \mathrm{L}}^{\prime \prime}=\mathrm{h}_{\mathrm{L}}\left(\mathrm{T}_{\mathrm{AD}}-\mathrm{T}_{\mathrm{S}, \mathrm{L}}\right)
$$

where $T_{S, L}$ is the absolute temperature of the ceiling's lower surface, $T_{A D}$ a characteristic gas temperature, is the temperature that would be measured adjacent to an adiabatic lower ceiling surface, and $h_{L}$ is a heat transfer coefficient. $h_{L}$ and $T_{A D}$ are given by

$$
\begin{gathered}
h_{\mathrm{L}} \tilde{\mathrm{h}}=\left\{\begin{array}{cc}
8.82 \mathrm{Re}_{\mathrm{H}}-1 / 2 \mathrm{Pr}^{-2 / 3}\left[1-\left(5.0-0.284 \mathrm{Re}_{\mathrm{H}} 0.2\right)(\mathrm{r} / \mathrm{H})\right] \\
\text { if } 0 \leq \mathrm{r} / \mathrm{H}<0.2 ; \\
0.283 \operatorname{Re}_{\mathrm{H}}-0.3 \operatorname{Pr}^{-2 / 3}(\mathrm{r} / \mathrm{H})^{-1.2}(\mathrm{r} / \mathrm{H}-0.0771) /(\mathrm{r} / \mathrm{H}+0.279) \\
\text { if } 0.2 \leq \mathrm{r} / \mathrm{H}
\end{array}\right. \\
\left(\mathrm{T}_{\mathrm{AD}}-\mathrm{T}_{\mathrm{U}}\right) /\left(\mathrm{T}_{\mathrm{U}} \mathrm{Q}_{\mathrm{H}}^{* 2 / 3}\right)=\left\{\begin{array}{c}
10.22-14.9 \mathrm{r} / \mathrm{H} \text { if } 0 \leq \mathrm{r} / \mathrm{H}<0.2 ; \\
8.39 \mathrm{f}(\mathrm{r} / \mathrm{H}) \text { if } 0.2 \leq \mathrm{r} / \mathrm{H}
\end{array}\right.
\end{gathered}
$$

where 


$$
\begin{aligned}
& \mathrm{f}(\mathrm{r} / \mathrm{H})=\left[1-1.10(\mathrm{r} / \mathrm{H})^{0.8}+0.808(\mathrm{r} / \mathrm{H})^{1.6}\right] / \\
& {\left[1-1.10(\mathrm{r} / \mathrm{H})^{0.8}+2.20(\mathrm{r} / \mathrm{H})^{1.6}+0.690(\mathrm{r} / \mathrm{H})^{2.4}\right]} \\
& \tilde{\mathrm{h}=} \rho_{\mathrm{U}} \mathrm{C}_{\mathrm{p}} \mathrm{g}^{1 / 2} \mathrm{Q}_{\mathrm{H}}^{* 1 / 3} ; \\
& \operatorname{Re}_{\mathrm{H}}=\mathrm{g}^{1 / 2} \mathrm{H}^{3 / 2} \mathrm{Q}_{\mathrm{H}}^{* 1 / 3} / \nu_{\mathrm{U}} ; \\
& \mathrm{Q}_{\mathrm{H}}^{*}=\mathrm{Q}^{\prime} /\left[\rho_{\mathrm{U}} \mathrm{C}_{\mathrm{p}} \mathrm{T}_{\mathrm{U}}(\mathrm{gH})^{1 / 2} \mathrm{H}^{2}\right]
\end{aligned}
$$

In the above, $\operatorname{Pr}$ is the Prandtl number (taken to be 0.7 ) and $v U$ is the kinematic viscosity of the upper layer gas which is assumed to have the properties of air. Also, $\mathrm{Q}_{\mathrm{H}}^{*}$, a dimensionless number, is a measure of the strength of the plume and $\mathrm{Re}_{\mathrm{H}}$ is a characteristic Reynolds number of the plume at the elevation of the ceiling.

The following estimate for $v_{\mathrm{U}}$ of air [16] will be used when computing $\mathrm{Re}_{\mathrm{H}}$ from Eqs. (41)

$$
v_{U} /\left(\mathrm{m}^{2} / \mathrm{s}\right)=\left[0.04128\left(\mathrm{~T}_{U} / \mathrm{K}\right)^{5 / 2} 10^{-7}\right] /\left[\left(\mathrm{T}_{U} / \mathrm{K}\right)+110.4\right]
$$

As the fire simulation proceeds, the ceiling's lower surface temperature, $\mathrm{T}_{S, L}$, initially at $\mathrm{T}_{\mathrm{AMB}}$, begins to increase. At all times the lower ceiling surface is assumed to radiate diffusely to the initially ambient-temperature floor surface and to exposed surfaces of the building contents. In response to this radiation, and to the direct radiation from the fire's combustion zone, the temperature of these surfaces also increase with time. However, for times of interest here it is assumed that the effective temperature increase of these floor/contents surfaces are relatively small compared to the characteristic increases of $T_{S, L}$. Accordingly, at a given radial position of the ceiling's lower surface, the net radiation exchange between the ceiling and the floor/contents surfaces can be approximated by

$$
\mathrm{q}_{\mathrm{RERAD}, \mathrm{L}}^{\prime \prime}=\sigma\left(\mathrm{T}_{\mathrm{AMB}}^{4}-\mathrm{T}_{\mathrm{S}, \mathrm{L}}^{4}\right) /\left(1 / \epsilon_{\mathrm{L}}+1 / \epsilon_{\mathrm{FLOOR}}-1\right)
$$

where $\sigma$ is the Stefan-Boltzmann constant and $\epsilon_{\mathrm{L}}$ and $\epsilon_{\mathrm{FLOOR}}$ are the effective emittance/absorptance of the assumed-grey ceiling upper surface and floor/contents surfaces, respectively, both of which will be taken to be 1 .

\subsubsection{Net Heat Transfer Flux to Ceiling's Upper Surface}

It is assumed that the ceiling's upper surface is exposed to a relatively constant-temperature far-field environment at temperature $T_{A M B}$. Then the net heat transfer flux to this surface, $q_{L}^{\prime \prime}$, is made up of two components, 
convection, $\mathrm{q}_{\mathrm{CON}, \mathrm{u}}$, and reradiation, $\mathrm{q}_{\mathrm{RERAD}, \mathrm{u}}$

$$
\mathrm{q}_{\mathrm{U}}^{\prime \prime}=\mathrm{q}_{\mathrm{CON}, \mathrm{U}}^{\prime \prime}+\mathrm{q}_{\mathrm{RERA}, \mathrm{U}}^{\prime \prime}
$$

These can be estimated from

$$
\begin{aligned}
& \mathrm{q}_{\mathrm{CONV}, \mathrm{U}}^{\prime \prime}=\mathrm{h}_{\mathrm{U}}\left(\mathrm{T}_{\mathrm{AMB}}-\mathrm{T}_{\mathrm{S}, \mathrm{U}}\right) \\
& \mathrm{q}_{\mathrm{RERAD}, \mathrm{U}}^{\prime \prime}=\sigma\left(\mathrm{T}_{\mathrm{AMB}}^{4}-\mathrm{T}_{\mathrm{S}, \mathrm{U}}^{4}\right) /\left(1 / \epsilon_{\mathrm{U}}+1 / \epsilon_{\mathrm{FAR}}-1\right)
\end{aligned}
$$

where $T_{S, U}$ is the absolute temperature of the upper surface of the ceiling, $h_{U}$ is a heat transfer coefficient, and $\epsilon_{\mathrm{FAR}}$ and $\epsilon_{\mathrm{U}}$ are the effective emittance/absorptance of the assumed-grey far-field and ceiling upper surface, respectively, both of which will be taken to be 1 .

The value for $h_{U}$ to be used here is [17]

$$
\mathrm{h}_{\mathrm{U}} /\left(\mathrm{W} / \mathrm{m}^{2}\right)=1.675\left|\left(\mathrm{~T}_{\mathrm{AMB}} / \mathrm{K}\right)-\left(\mathrm{T}_{\mathrm{S}, \mathrm{U}} / \mathrm{K}\right)\right|^{1 / 3}
$$

\subsubsection{Solving for the Thermal Response of the Ceiling and for $\mathrm{q}_{\mathrm{B}} \mathrm{T}$}

The temperature of the ceiling material is assumed to be governed by the Fourier heat conduction equation. By way of the lower ceiling surface boundary condition, the boundary value problem is coupled to, and must be solved together with the system of Eqns (6) and $\left(7^{\prime}\right)$.

Initially the ceiling is taken to be of uniform temperature, $\mathrm{T}_{\mathrm{AMB}}$. The upper and lower ceiling surfaces are then exposed to the radial- and time-dependent rates of heat transfer $q_{u}^{\prime \prime}$ and $q_{L}^{\prime \prime}$, determined from Eqs. (44) and (35), respectively. For times of interest here, radial gradients of $\mathrm{q}_{\mathrm{u}}^{\prime \prime}$ and $\mathrm{q}_{\mathrm{L}}^{\prime \prime}$ are assumed to be small enough so that conduction in the ceiling is quasi-onedimensional in space, i.e., $\mathrm{T}=\mathrm{T}(\mathrm{Z}, \mathrm{t} ; \mathrm{r})$. Thus, the two-dimensional thermal response for the ceiling can be obtained from the solution to a set of onedimensional conduction problems for $T_{n}(Z, t)=T\left(Z, t ; r=r_{n}\right), n=1$ to NRAD, where NRAD is the number of discrete radial position required to obtain a sufficiently smooth representation of the overall ceiling temperature distribution.

The parametric study of [14] for the thermal response of unconfined ceilings above constant and growing fires indicates generally that changes in $T$ occur smoothly over the radial distances of order one when scaled by $H$, i.e., $d\left(T / T_{\text {MAX }}\right) / d(r / H)=0(1)$, where $T_{M A X}(t)=T_{S, L}(r=0, t)=T(Z=0, t ; r=0)$. Thus, it is reasonable to expect accurate results for the Eq. (33) integral of the 
q"ONV, L distribution, which depends on the radial distribution of $\mathrm{T}_{S, L}(r, t)=\mathrm{T}(Z=0, t ; r)$ through Eq. (37), by carrying out the following procedure: Choose NRAD as several times $D_{E F F} /\left[2\left(y_{C E I L}-y_{F I R E}\right)\right]$, where the latter value is assumed to be $>0.2$ (here we choose NRAD as the first integer equal to or greater than $\left.5 D_{E F F} /\left[2\left(y_{C E I L}-y_{F I R E}\right)\right]+2\right) ;$ place one node point at $r=0$ and distribute with uniform separation the remaining NRAD radial node points at and between $r=0.2\left(y_{C E I L}-y_{F I R E}\right.$ ) and $r=D_{E F F} / 2$; solve for the NRAD temperature distributions $\mathrm{T}_{n}$ and use the lower surface values of these, the $T_{S, L, n}(t)=T_{S, L}\left(r=r_{n}, t\right)=T_{n}\left(Z=0, t ; r=r_{n}\right)$, to compute the corresponding discrete values of $q_{C O N V, L, n}(t)=q_{C O N V, L}\left(r=r_{n}, t\right)$ from Eq. (37); approximate the $q_{C O N V, L}$ distribution in ' $r$ by interpolating between the $q_{C O N}^{\prime \prime}, \mathrm{L}, \mathrm{n}$ (here we will use linear interpolation); and carry out the integration indicated in $\mathrm{Eq} .(33)$.

The procedure for solving for the $T_{n}$ is the same as that used in [14]. It requires the thickness, thermal conductivity and thermal diffusivity of the ceiling material. The solution to the one-dimensional heat conduction equation involves an explicit finite difference scheme which uses the algorithm taken from $[18,19]$. For a given set of calculations, $\mathrm{N} \leq 20$ equalspaced nodes are positioned at the surfaces and through the thickness of the ceiling at every radius position $r_{n}$. The spacing, $\delta z$, of these is selected to be large enough (based on a maximum time step) to insure stability of the calculation.

\section{Actuation of Vents and Sprinklers by Near-Ceiling-Deployed Fusible Links}

It is an objective of this work to simulate conditions in building spaces where ceiling vents and sprinkler links can be actuated by the responses of near-ceiling-deployed fusible links. The idea is that during the course of a compartment fire a deployed link will be engulfed by the near-ceiling convective flow of the elevated-temperature products of combustion and entrained air of the fire-generated plume. As the fire continues, convective heating of the link will lead to an increase in its temperature. If and when its fuse temperature is reached, the device(s) being operated by the link will be actuated.

The near-ceiling flow engulfing the link is the plume-driven ceiling jet, refered to earlier, which transfers heat to the lower ceiling surface and is cooled as it traverses under the ceiling from the point of plume-ceiling impingement. In the case of relatively smooth-ceiling configurations, assumed to be representative of the facilities studied in this work, the ceiling jet flows outward radially from this point of impingement and its gas velocity and temperature distributions, $V_{C J}$ and $T_{C J}$, respectively, are a function of radius from the impingement point, $r$, distance below the ceiling, $z$, and time.

\subsection{Predicting the Thermal Response of the Fusible Links}

We calculate the thermal response of deployed fusible links, up to their fuse temperature, $T_{F}$, by the convective heating flow model developed in [20]. We 
assume that a link of interest is positioned at a specified radius from the impingement point, $r=r_{L}$, and distance below the lower ceiling surface, $z=z_{L}$. We define $\mathrm{T}_{\mathrm{L}}$ as the link's assumed-near-uniform temperature. Then

instantaneous changes in $\mathrm{T}_{\mathrm{L}}$ are determined by

$$
\mathrm{dT}_{\mathrm{L}} / \mathrm{dt}=\left(\mathrm{T}_{\mathrm{CJ}, \mathrm{L}}-\mathrm{T}_{\mathrm{L}}\right) \mathrm{V}_{\mathrm{CJ}, \mathrm{L}}{ }^{1 / 2} / \mathrm{RTI}
$$

where $\mathrm{T}_{\mathrm{CJ}, \mathrm{L}}$ and $\mathrm{V}_{\mathrm{CJ}, \mathrm{L}}$ are the values of $\mathrm{T}_{\mathrm{CJ}}$ and $\mathrm{V}_{\mathrm{CJ}}$, respectively, evaluated local to the link position and where RTI (Response Time Index), a property of the link and relative flow orientation, can be measured in the "plunge test" described in [20, 21]. RTI's for ordinary sprinkler links range from a low values of $22(\mathrm{~m} \cdot \mathrm{s})^{1 / 2}$ for quick operating residential sprinklers, to $375(\mathrm{~m} \cdot \mathrm{s})^{1 / 2}$ for slower standard sprinklers [22]. The utility of Eq. (48), which is shown in [23] to be valid typically through the link fusing process, is discussed further in [22] and actually used there to predict link response in a parametric study involving two-layer compartment fire scenarios. Also, the link response prediction methodology of the latter study was used in the work of reference [22] which reports favorable comparisons between predicted and measured link responses in a full-scale, one-room, open-doorway compartment fire experiment.

To compute $\mathrm{T}_{\mathrm{L}}$ from Eq. (48) for a different link locations requires estimates of $\mathrm{V}_{\mathrm{CJ}, \mathrm{L}}$ and $\mathrm{T}_{\mathrm{CJ}, \mathrm{L}}$ for arbitrary link position, $\mathrm{r}_{\mathrm{L}}$ and $\mathrm{z}_{\mathrm{L}}$.

\subsection{The Velocity Distribution of the Ceiling Jet}

Outside of the plume/ceiling impingement stagnation zone, defined approximately by $\mathrm{r} / \mathrm{H} \geq 0.2$, and at a given $r, V_{\mathrm{CJ}}$ rises rapidly from zero at the ceiling's lower surface, $z=0$, to a maximum, $V_{M A x}$, at a distance $z=0.23 \delta, \delta(r)$ being the distance below the ceiling where $V / \mathrm{V}_{\mathrm{MAX}}=1 / 2$ [15]. In this region outside the stagnation zone, $V_{C J}$ can be estimated from [15]

when $r / H \geq 0.2$ :

$\mathrm{V}_{\mathrm{CJ}} / \mathrm{V}_{\mathrm{MAX}}= \begin{cases}(8 / 7)[z /(0.23 \delta)]^{1 / 7}(1-[z /(0.23 \delta)] / 8\}, & 0 \leq z /(0.23 \delta) \leq 1 \\ \cosh ^{-2}\left\{(0.23 / 0.77) \operatorname{arccosh}\left(2^{1 / 2}\right)[z /(0.23 \delta)-1]\right\}, 1 \leq z /(0.23 \delta)\end{cases}$

$\mathrm{V}_{\mathrm{MAX}} / \mathrm{V}=0.85(\mathrm{r} / \mathrm{H})^{-1.1} ; \delta / \mathrm{H}=0.10(\mathrm{r} / \mathrm{H})^{0.9} ; \mathrm{V}=\mathrm{g}^{1 / 2} \mathrm{H}^{1 / 2} \mathrm{Q}_{\mathrm{H}}^{* 1 / 3}$ 
where $\mathrm{Q}_{\mathrm{H}}^{*}$ is defined in Eq. (41). $\mathrm{V}_{\mathrm{CJ}} / \mathrm{V}_{\mathrm{MAX}}$ per Eq. (49) is plotted in Figure 3.

In the vicinity of near-ceiling-deployed links located inside the stagnation zone, the fire-driven flow is changing directions from an upward-directed plume flow to a outward-directed ceiling-jet-type flow. There the flow velocity local to the link, the velocity which drives the link's convective heat transfer, involves generally a significant vertical as well as radial component of velocity. Nevertheless, at such link locations it is reasonable to continue to approximate the link response by $\mathrm{Eq}$. (48) with $\mathrm{V}_{\mathrm{CJ}}$ estimated by Eqs. (49) and (50) and with $\mathrm{r} / \mathrm{H}$ is set equal to 0.2 , i.e.,

when $0 \leq \mathrm{r} / \mathrm{H}<0.2$

$$
\mathrm{V}_{\mathrm{CJ}}=\mathrm{V}_{\mathrm{CJ}}(\mathrm{r} / \mathrm{H}=0.2)
$$

This approximation is adopted here.

\subsection{The Temperature Distribution of the Ceiling Jet}

Outside of the plume-ceiling impingement stagnation zone, i.e., where $r / H \geq 0.2$, and at a given value of $r, T_{C J}$ rises very rapidly from the temperature of the ceiling's lower surface $T_{S}, L$, at $z=0$, to a maximum, $T_{M A X}$, somewhat below the ceiling surface. We assume that this maximum value of $\mathrm{T}_{\mathrm{CJ}}$ occurs at the identical distance below the ceiling as does the maximum of $V_{C J}$, i.e., at $z=0.23 \delta$. Below this elevation, $T_{C J}$ drops with increasing distance from the ceiling until it reaches the upper layer temperature, $\mathrm{T}_{\mathrm{U}}$. In this latter, outer region of the ceiling jet, the shape of the normalized $\mathrm{T}_{C \mathrm{~J}}$ distribution, $\left(\mathrm{T}_{\mathrm{CJ}}-\mathrm{T}_{U}\right) /\left(\mathrm{T}_{\mathrm{MAX}}-\mathrm{T}_{U}\right)$, will have the same characteristics as does that of $\mathrm{V}_{\mathrm{CJ}} / \mathrm{V}_{\mathrm{MAX}}$. Also, since we are dealing with a turbulent boundary flow it is reasonable to expect that the characteristic thicknesses of the outer region of both the velocity and temperature distributions are the same, being dictated there by the distribution of the turbulent eddies.

For the above reasons we approximate the velocity and temperature distributions as being identical in the outer region of the ceiling jet flow, $0.23 \delta \leq z$. In the inner region of the flow, between $z=0$ and $0.23 \delta$, we approximate the normalized temperature distribution by a quadratic function of $\mathrm{z} /(0.23 \delta)$, requiring $\mathrm{T}_{\mathrm{CJ}}=\mathrm{T}_{\mathrm{S}, \mathrm{L}}$ at $\mathrm{z}=0$ and $\mathrm{T}_{\mathrm{CJ}}=\mathrm{T}_{\mathrm{MAX}}, \mathrm{dT}_{\mathrm{CJ}} / \mathrm{dz}=0$ at $\mathrm{z}=0.23 \delta$. Thus, 
when $\mathrm{r} / \mathrm{H} \geq 0.2$ :

$\Theta \equiv\left(\mathrm{T}_{\mathrm{CJ}}-\mathrm{T}_{\mathrm{U}}\right) /\left(\mathrm{T}_{\mathrm{MAX}}-\mathrm{T}_{U}\right)= \begin{cases}\theta_{\mathrm{S}}+2\left(1-\theta_{\mathrm{S}}\right)[\mathrm{z} /(0.23 \delta)]-\left(1-\theta_{\mathrm{S}}\right)[\mathrm{z} /(0.23 \delta)]^{2} \\ \\ \mathrm{~V}_{\mathrm{CJ}} / \mathrm{V}_{\mathrm{MAX}}, \quad 1 \leq \mathrm{z} /(0.23 \delta)\end{cases}$

$\Theta_{S} \equiv \Theta\left(T_{C J}=T_{S, L}\right)=\left(T_{S, L}-T_{U}\right) /\left(T_{M A X}-T_{U}\right)$

Note that $\theta_{\mathrm{S}}$ will be negative when the ceiling surface temperature is less than the upper layer temperature, for example, relatively early in the fire when the original ambient-temperature ceiling surface has not yet reached the average temperature of the growing upper layer. Also, $\theta_{S}$ will be greater than 1 when the ceiling surface temperature is greater than $\mathrm{T}_{\mathrm{MAX}}$. This is possible, for example, during times of reduced fire size when the fire's nearceiling plume temperature is reduced significantly, perhaps temporarily, from previous values, but the ceiling surface, heated previously to relatively high temperatures, has not cooled substantially. Plots of $\theta$ per Eq. (52) are presented in Figure 4 for cases when $\Theta_{S}$ is $<0$, between 0 and 1 , and $>0$.

In a manner similar to the treatment of $\mathrm{V}_{\mathrm{CJ}} / \mathrm{V}_{\mathrm{MAX}}$, for the purpose of calculating $\mathrm{T}_{\mathrm{L}}$ from Eq. (48) we approximate $\Theta_{\mathrm{S}}$ inside the stagnation zone by the description of Eqs. (52) and (53) with $\mathrm{r} / \mathrm{H}$ set equal to 0.2 , i.e.,

when $0 \leq \mathrm{r} / \mathrm{H} \leq 0.2$ :

$$
\Theta_{\mathrm{S}}=\Theta_{\mathrm{S}}(\mathrm{r} / \mathrm{H}=0.2)
$$

With the radial distribution for $\mathrm{T}_{\mathrm{S}, \mathrm{L}}$ and $\mathrm{T}_{\mathrm{U}}$ already calculated up to a particular time of interest, only $\mathrm{T}_{\mathrm{MAX}}^{\mathrm{i}}$ is required to complete the Eqs. (52)(54) estimate for the ceiling jet temperature distribution. This is obtained by invoking conservation of energy. Thus, at an arbitrary $r$ outside the stagnation zone the total rate of radial outflow of enthalpy (relative to the upper layer temperature) of the ceiling jet is equal to the uniform rate of enthalpy flow in the upper layer portion of the plume, $Q^{\prime}$, less the integral (from the plume-ceiling impingement point to $r$ ) of the flux of convective heat transfer from the ceiling jet to the ceiling surface, i.e., 
when $0.2 \leq r / H$ :

$$
2 \pi \int_{0}^{\infty} \rho_{U} C_{p}\left(T_{C J}-T_{U}\right) V_{C J} z d z=Q^{\prime}-2 \pi \int_{0}^{r} \mathrm{q}_{C O N V, L}^{\prime \prime}(r, t) r d r \equiv\left(1-\lambda_{C O N V}^{\prime}\right) Q^{\prime}
$$

$\lambda_{\text {CONV }}$ is the fraction of $Q^{\prime}$ transferred by convection to the ceiling from the point of ceiling impingement to $r$, i.e.,

$$
\lambda_{C O N V}^{\prime}(r)=\left[2 \pi \int_{0}^{r} q_{C O N V, L}^{\prime \prime}(r, t) r d r\right] / Q^{\prime}
$$

In Eqs. (55) and (56), Q' has been calculated previously in Eqs. (41). Also, the integral on the right hand sides of Eqs. (55) and (56) can be calculated by approximating $q_{C O N}, L(r, t)$, as discussed above in section 3.4.3.3, as a linear function of $r$ between previously calculated values of $q_{C O N V, L}\left(r=r_{n}, t\right)$.

The integral on the left hand side of Eq. (55) is calculated using $\mathrm{V}_{\mathrm{CJ}}$ of Eqs. (49) and (50) and $T_{C J}$ of Eqs. (52) and (53). From this the desired distribution for $\mathrm{T}_{\mathrm{MAX}}$ is found finally to be

$$
\begin{array}{r}
\left(\mathrm{T}_{\mathrm{MAX}}-\mathrm{T}_{\mathrm{U}}\right)=2.6\left(1-\lambda_{\mathrm{CONV}}^{\prime}\right)(\mathrm{r} / \mathrm{H})^{-0.8} \mathrm{Q}_{\mathrm{H}}^{* 2 / 3} \mathrm{~T}_{\mathrm{U}}-0.090\left(\mathrm{~T}_{\mathrm{S}}-\mathrm{T}_{\mathrm{U}}\right) \\
0.2 \leq \mathrm{r} / \mathrm{H}
\end{array}
$$

The above result together with Eqs. (52) and (53) represent the desired estimate for $T_{C J}$. This and the Eqs. (49)-(51) estimate for $V_{C J}$ are used to calculate $\mathrm{T}_{\mathrm{L}}$ from Eq. (48).

\subsection{Dependence of Open Vent Area on Fusible Link-Actuated Vents}

As discussed above in section 3.1, the influence of ceiling vent action on the fire-generated environment is dependent on the active area of the open ceiling vents, $A_{V}$. A variety of basic vent opening design strategies are possible and it is a major purpose of this work to evaluate these within the context of the developing fire environment. For example, one of the simplest strategies, the one examined in reference [1], assumes that all vents deployed in the curtained area of interest are opened by whatever means at the onset of the fire. In general $A_{v}$ will be time-dependent. To the extent that a strategy of vent opening is dependent directly on the fusing of any one or several deployed fusible links, the location of these links and their characteristics (i.e., likely spacings from plume-ceiling impingement, distance below the ceiling, and the RTI) and the functional relation between link fusing and $A_{V}$ must be specified. These matters, to be examined in the context of different solutions to the overall problem, will be addressed in [2]. 


\section{Initiating the Solution of the Model Equations}

The basic independent variables describing the fire-generated environment are $y$ and $\rho_{U}$. These are determined from the solution to Eqs. (6) and ( $7^{\prime}$ ), respectively. The right hand sides of these latter equations depend on the time-dependent values of $\mathrm{m}_{U}$ and $\mathrm{q}_{U}$ which are computed from Eqs. (4) and (5), respectively, through use of the variety of algorithms described in this work.

The solution to the governing equations requires the initial value of $y$ and $\rho_{\mathrm{U}}$. The first of these is specified to be $\mathrm{y}_{\mathrm{CEIL}}$. The second must be determined from Eq. (8). But this calls for initial values for $\mathrm{m}_{U}$ and $\mathrm{q}_{U}$ which are not available. Therefore, the determination of $\rho_{U}(t=0)$ requires the special considerations described below.

$\mathrm{m}_{U}$ and $\mathrm{q}_{U}$ are determined by evaluating the individual terms on the right hand sides of Eqs. (4) and (5) as follows.

Since $y-y_{C E I L}=0, m_{V E N T}=0$ from Eq. (12) and $q_{V E N T}=0$ from Eq. (13). Since $\mathrm{y}_{\mathrm{CU}} \mathrm{R}_{\mathrm{T}}-\mathrm{y}<0, \mathrm{~m}_{\mathrm{C} U \mathrm{RT}}=0$ from Eq. (20) and $\mathrm{q}_{\mathrm{CURT}}=0$ from Eq. (21).

From the initial characteristics of the fire, $Q>0, y_{F I R E}$, and $D_{F I R E}$, compute $\mathrm{L}_{\mathrm{FLAME}}$ from Eq. (17). Using this, calculate $\left(\mathrm{y}-\mathrm{y}_{\mathrm{FIRE}}\right) / \mathrm{L}_{\mathrm{FLAME}}$. Determine $m_{P L} U_{M E}$ from Eq. (16), $m_{E N T}$ from Eq. (14), and then $q_{P L U M E}=m_{E N T} C_{p} T_{A M B}+\left(1-\lambda_{r}\right) Q$ from Eq. (15).

At this stage of the calculation, use of Eqs. (8) and (3) together with the above results leads to the following equation for the unknown $T_{U}(t=0)$

$$
T_{U}(t=0)-\left[m_{E N T} C_{p} T_{A M B}+\left(1-\lambda_{r}\right) Q+q_{H T}\right] /\left(m_{E N T} C_{v}\right)=0
$$

Except for $T_{U}(t=0), q_{H T}$ is the only remaining unknown in Eq. (58).

Furthermore, at time $t=0$ of interest $q_{H T}$ is a function of $T_{U}(t=0)$, i.e., $\mathrm{q}_{\mathrm{HT}}=\mathrm{f}\left(\mathrm{T}_{\mathrm{U}}\right)$. Since $\mathrm{q}_{\mathrm{H} T}$ is in the range

$$
-\left(1-\lambda_{\mathrm{r}}\right) \mathrm{Q}<\mathrm{q}_{\mathrm{HT}}<0
$$

it follows that the unknown $T_{U}(t=0)$ is the presumably unique root of Eq. (58) which lies within the range

$$
\mathrm{T}_{\mathrm{AMB}}<\mathrm{T}_{\mathrm{U}}(t=0)<\left[\mathrm{m}_{\mathrm{ENT}} \mathrm{C}_{\mathrm{p}} \mathrm{T}_{\mathrm{AMB}}+\left(1-\lambda_{\mathrm{r}}\right) \mathrm{Q}\right] /\left(\mathrm{m}_{\mathrm{ENT}} \mathrm{C}_{\mathrm{v}}\right)
$$

The functional relationship between $\mathrm{q}_{\mathrm{H} T}$ and $\mathrm{T}_{\mathrm{U}}(t=0)$ is determined from Eqs. (25) $-(34)$ and (37)-(42) where $\mathrm{T}_{\mathrm{S}, \mathrm{L}}=\mathrm{T}_{\mathrm{AMB}}$ in $\mathrm{Eq}$. (37). Thus, for each node point at $r=r_{n}$ on the lower ceiling surface, $q_{C O N v, L, n}(t=0)$ is computed from 
Eq. (37) and, as discussed in the third paragraph of section 3.4.3.3, $\mathrm{q}_{\mathrm{HT}}$ is obtained finally from Eq. (33).

\section{Concluding Remarks}

The theory presented here is the basis of a computer model now under development. This will be used to study parametrically a wide range of relevant fire scenarios. The results of the parametric study will be presented in Part II of this work [2]: Estimating the Environment and the Response of Sprinkler Links in Compartment Fires with Draft Curtains and Fusible Link-Actuated Ceiling Vents - Part II: Application (tentative title).

\section{Acknowledgements}

The author acknowledges gratefully the AAMA Research Foundation which supported this work. 


\section{References}

[1]. Hinkley, P.L., The Effect of Vents on the Opening of the First Sprinklers, Fire Safety Journal, 11, pp. 211-225, 1986.

[2]. Walton, D.W., Cooper, L.Y., and Stroup, D.W., Estimating the Environment and the Response of Sprinkler Links in Compartment Fires with Draft Curtains and Fusible Link-Actuated Ceiling Vents - Part II: Application (tentative title), to be published.

[3]. Emmons, H.W., The Flow of Gases Through Vents, Harvard University Home Fire Project Technical Report No. 75, March 16, 1987.

[4]. Thomas, P.H., et al, Investigations Into the Flow of Hot Gases in Roof Venting, Fire Research Technical Paper No. 7, HMSO, London, 1963.

[5]. Heskestad, G., Smoke Movement and Venting, Fire Safety Journal, 11, pp77-83, 1986, and Appendix A: Guide for Heat and Smoke Venting, NFPA 204M, National Fire Protection Association, Quincy, MA, 1982.

[6]. Cooper, L.Y., A Mathematical Model for Estimating Available Safe Egress Time in Fires, Fire and Materials, 6, 3/4, pp. 135-144, 1982.

[7]. Heskestad, G., Engineering Relations for Fire Plumes, Fire Safety Journal, 7, pp. 25-32,1984.

[8]. Hinkley, P.L., Rates of 'Production' of Hot Gases in Roof Venting Experiments, Fire Safety Journal, 10, pp. 57-65, 1986.

[9]. Zukoski, e.e., Kubota, T., and Cetegen, B., Fire Safety Journa1, 3, p $107,1981$.

[10]. Cooper, L.Y., A Buoyant Source in the Lower of Two, Homogeneous, Stably Stratified Layers, 20th International Symposium on Combustion, Combustion Institute, pp. 1567-1573, 1984.

[11]. Cooper, L.Y., Convective Heat Transfer to Ceilings Above Enclosure Fires, Cooper, L.Y., 19th Symposium (International) on Combustion, Combustion Institute, pp. 933-939 (1982).

[12]. Cooper, L.Y., Heat Transfer From a Buoyant Plume to an Unconfined Ceiling, Journal of Heat Transfer, Vo1. 104, pp. 446-451, Aug. 1982.

[13]. Cooper, L.Y. and Woodhouse,A., The Buoyant Plume-Driven Adiabatic Ceiling Temperature Revisited, Journal of Heat Transfer, Vol. 108, pp. $822-826$, Nov. , 1986.

[14]. Cooper, L.Y., and Stroup, D.W., Thermal Response of Unconfined Ceilings Above Growing Fires and the Importance of Convective Heat Transfer, Journal of Heat Transfer, Vo1. 109, pp. 172-178, Feb. 1987. 
[15]. Cooper, L.Y., Ceiling Jet-Driven Wall Flows in Compartment Fires, NBSIR 87-3535, National Bureau of Standards, Gaithersburg, MD, April, 1987.

[16]. Hilsenrath, J., Tables of Thermal Properties of Gases, Circular 564, National Bureau of Standards, Gaithersburg, MD, Nov. 1955.

[17]. Yousef, W.W., Tarasuk, J.D., and McKeen, W.J., Free Convection Heat Transfer From Upward-Facing, Isothermal, Horizontal Surfaces, Journal of Heat Transfer, Vol. 104, pp. 493-499, Aug. 1982.

[18]. Emmons, H.W., The Prediction of Fire in Buildings, 17th Symposium (International) on Combustion, Combustion Institute, pp. 1101-1111 (1979).

[19]. Mitler, H.E., and Emmons, H.W., Documentation for the Fifth Harvard Computer Fire Code, Home Fire Project Tech. Report 45, Harvard University, Cambridge, MA. 1981.

[20]. Heskestad, G. and Smith, H.F., Investigation of a New Sprinkler Sensitivity Approval Test: The Plunge Test, Technical Report Serial No. 22485, RC 76-T-50, Factory Mutual Research Corporation, Norwood, MA, 1976.

[21]. Heskestad, G., The Sprinkler Response Time Index (RTI), Paper RC-81-TP-3 presented at the Technical Conference on Residential Sprinkler Systems, Factory Mutual Research Corporation, Norwood, MA, April 28-29, 1981.

[22]. Evans, D.D., Calculating Sprinkler Actuation Times in Compartments, Fire Safety Journal, 9, pp 147-155, 1985.

[23]. Evans, D.D., Characterizing the Thermal Response of Fusible Link Sprinklers, NBSIR 81-2329, National Bureau of Standards, Gaithersburg, MD, 1981 .

[24]. Cooper, L.Y. and Stroup, D.W., Test Results and Predictions for the Response of Near-Ceiling Sprinkler Links in Full-Scale Compartment Fires, NBSIR 87-3663, National Bureau of Standards, Gaithersburg, MD, 1987, to be presented at the 2nd International Symposium on Fire Safety Science, Tokyo, June, 1988 and published in the Symposium Proceedings. 


\section{Nomenclature}

A

$\mathrm{A}_{\mathrm{EFF}}$

$\mathrm{A}_{\mathrm{V}}$

C

$\mathrm{C}_{\mathrm{p}}$

$\mathrm{C}_{\mathrm{T}}$

$\mathrm{C}_{\mathrm{v}}$

$D_{E F F}$

DF IRE

g

$\mathrm{H}$

$\sim$

$\mathrm{h}$

$h_{L}, h_{U}$

IF LAME

$\mathrm{m}^{*}$

$m_{C U R T}$

$\mathrm{m}_{\mathrm{ENT}}$

$\mathrm{m}_{\text {PLUME }}$

$m_{U}$

$\mathrm{m}_{\mathrm{VEN} \mathrm{T}}$

$\mathrm{N}$

NRAD

$\mathrm{P}$ plan area of single curtained space

effective area for heat transfer to the extended lower ceiling surface, $\pi D_{E F F}^{2} / 4$

total vent area of curtained space

vent flow coefficient $(\simeq 0.68)$

specific heat at constant pressure

9.115, dimensionless constant in plume model

specific heat at constant volume, $C_{p} / \gamma$

effective diameter of $A_{E F F}$

effective diameter of fire source $\left(\pi D_{\text {FIRE }}^{2} / 4=\right.$ area of fire source)

acceleration of gravity

distance below ceiling of equivalent source

characteristic heat transfer coefficient

lower, upper ceiling surface heat transfer coefficient

flame length

fraction of $m_{P L U M E}$ which is buoyant relative to $T_{U}$

mass flow rate from below curtain to upper layer

rate of plume mass entrainment between fire and layer interface

mass flow rate of plume at interface

net mass flow rate to upper layer

mass flow rate through ceiling vents to upper layer

number of equal-spaced nodes through the ceiling

number of values of $r_{n}$

length of perimeter of single curtained area. 
$\operatorname{Pr}$

$\mathrm{p}$

$\mathrm{P}_{U}, \mathrm{P}_{\mathrm{AMB}}$

Q

$Q^{\prime}$

$\mathrm{Q}_{\mathrm{B}}^{\star}$

$\mathrm{Q}_{\mathrm{E} \mathrm{Q}}^{*}$

$q_{\text {CONV, L }}, q_{\text {CONV, U }}$

$\mathrm{q}_{\mathrm{C} U R T}$

$\mathrm{q}_{\mathrm{H} \mathrm{T}}$

$\mathrm{q}_{\mathrm{PLUME}}$

$\mathrm{q}_{\mathrm{RAD}-\mathrm{FIRE}}^{\prime \prime}$

$q_{R E R A D, I}^{\prime \prime}, q_{R E R A D, u}^{\prime \prime}$

$\mathrm{q}_{\mathrm{U}}$

$q_{L}^{\prime \prime}, q_{U}^{\prime \prime}$

$\mathrm{q}_{\text {VEN T }}$

$\mathrm{q}_{\mathrm{CON}, \mathrm{L}, \mathrm{n}}$

R

$\mathrm{Re}_{\mathrm{H}}$

RTI

r

$r_{\mathrm{L}}$

$r_{n}$

$\mathrm{T}$
Prandtl number, taken to be 0.7

$P_{A M B}$ at floor elevation

pressure in upper layer, outside ambient

energy release rate of fire

strength of continuation source in extended upper

layer

dimensionless strength of plume at ceiling

dimensionless strength of plume at interface

convective heat transfer flux to lower, upper ceiling surface

enthalpy flow rate from below curtain to upper layer

heat transfer rate to upper layer

enthalpy flow rate of plume at interface

radiation flux incident on lower surface of ceiling

reradiation flux to lower, upper surface of ceiling

net enthalpy flow rate plus heat transfer rate to upper layer

net heat transfer fluxes to upper, lower ceiling surface

enthalpy flow rate through ceiling vent to upper layer

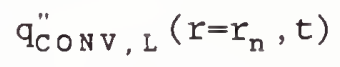

gas constant, $(\gamma-1) C_{p} / \gamma=C_{p}-C_{v}$

Reynolds number of plume at ceiling elevation

Response Time Index

radial distance from point of plume-ceiling

impingement

r at 1 ink

discrete values of $r$

absolute temperature of ceiling material 


\begin{tabular}{|c|c|}
\hline $\mathrm{T}_{\mathrm{AD}}$ & adiabatic lower ceiling surface temperature \\
\hline $\mathrm{T}_{\mathrm{CJ}}$ & temperature distribution of ceiling jet gas \\
\hline $\mathrm{T}_{\mathrm{CJ}, \mathrm{L}}$ & $\mathrm{T}_{\mathrm{CJ}}$ at $1 \mathrm{ink}$ \\
\hline $\mathrm{T}_{\mathrm{MAX}}(\mathrm{t})$ & $\mathrm{T}_{\mathrm{S}, \mathrm{L}}(\mathrm{r}=0, \mathrm{t})=\mathrm{T}(\mathrm{Z}=0, \mathrm{t} ; \mathrm{r}=0)$ \\
\hline $\mathrm{T}_{\mathrm{S}, \mathrm{L}}, \mathrm{T}_{\mathrm{S}, \mathrm{U}}$ & absolute temperature of lower, upper ceiling surface \\
\hline$T_{S, L, n}(t)$ & $T_{S, L}\left(r=r_{n}, t\right)=T_{n}\left(Z=0, t ; r=r_{n}\right)$ \\
\hline $\mathrm{T}_{U}, \mathrm{~T}_{\mathrm{AMB}}$ & absolute temperature of upper layer, outside ambient \\
\hline$T_{n}$ & $T\left(z, t ; r=r_{n}\right)$ \\
\hline t & time \\
\hline $\mathrm{v}$ & average flow velocity through all open vents \\
\hline $\mathrm{V}_{\mathrm{CJ}}$ & velocity distribution of ceiling jet gas \\
\hline $\mathrm{V}_{\mathrm{CJ}, \mathrm{L}}$ & $\mathrm{V}_{\mathrm{CJ}}$ at link \\
\hline $\mathrm{V}_{\mathrm{MAX}}$ & maximum value of $V_{C J}$ at a given $r$ \\
\hline$y, y_{C E I L}, y_{C U R T}, y_{F I R E}$ & $\begin{array}{l}\text { elevation of smoke layer interface, ceiling, bottom of } \\
\text { curtain, fire above floor }\end{array}$ \\
\hline Y'SOURCE & $\begin{array}{l}\text { elevation of plume continuation point source in } \\
\text { extended upper layer above floor }\end{array}$ \\
\hline $\mathrm{z}$ & $\begin{array}{l}\text { distance into the ceiling, measured from bottom } \\
\text { surface }\end{array}$ \\
\hline$z, z_{L}$ & distance below lower ceiling surface, $z$ at link \\
\hline$\alpha$ & $\mathrm{T}_{U} / \mathrm{T}_{\mathrm{AMB}}$ \\
\hline$\gamma$ & ratio of specific heats, $C_{p} / C_{v}$ \\
\hline$\Delta \mathrm{p}_{\mathrm{CEIL}}$ & cross-vent pressure difference \\
\hline$\triangle \mathrm{P}_{\mathrm{CURT}}$ & cross-curtain pressure difference \\
\hline$\delta$ & value of $z$ where $V_{C J}=V_{M A X}$ \\
\hline$\delta \mathrm{Z}$ & distance between nodes through the ceiling thickness \\
\hline & constant, Eq. (18) \\
\hline
\end{tabular}


$\epsilon_{\mathrm{L}}, \epsilon_{\mathrm{U}}, \epsilon_{\mathrm{FLOOR}}, \epsilon_{\mathrm{FAR}}$

$\Theta$

$\Theta_{\mathrm{S}}$

$\lambda_{r}$

$\lambda_{\text {CONV }}$

$\lambda_{\text {CONV }}^{\prime}$

$v_{U}$

$\rho_{U}, \rho_{\mathrm{AMB}}$

$\sigma$ emittance/absorptance of lower, upper, floor, and far field grey surfaces, all taken to be 1

normalized, dimensionless ceiling jet temperature distribution, $\left(\mathrm{T}_{\mathrm{CJ}}-\mathrm{T}_{\mathrm{U}}\right) /\left(\mathrm{T}_{\mathrm{MAX}}-\mathrm{T}_{\mathrm{U}}\right)$

$\Theta$ at the lower ceiling surface, $\left(T_{S, L}-T_{U}\right) /\left(T_{M A X}-T_{U}\right)$

fraction of $Q$ radiated from combustion zone

fraction of $Q$ transferred by convection from upper layer

fraction of $Q^{\prime}$ transferred to the ceiling in a circle of radius $r$, and centered at $r=0$, Eq. (56).

kinematic viscosity of upper layer gas

density of upper layer, outside ambient

dimensionless variable, Eq. (20) 


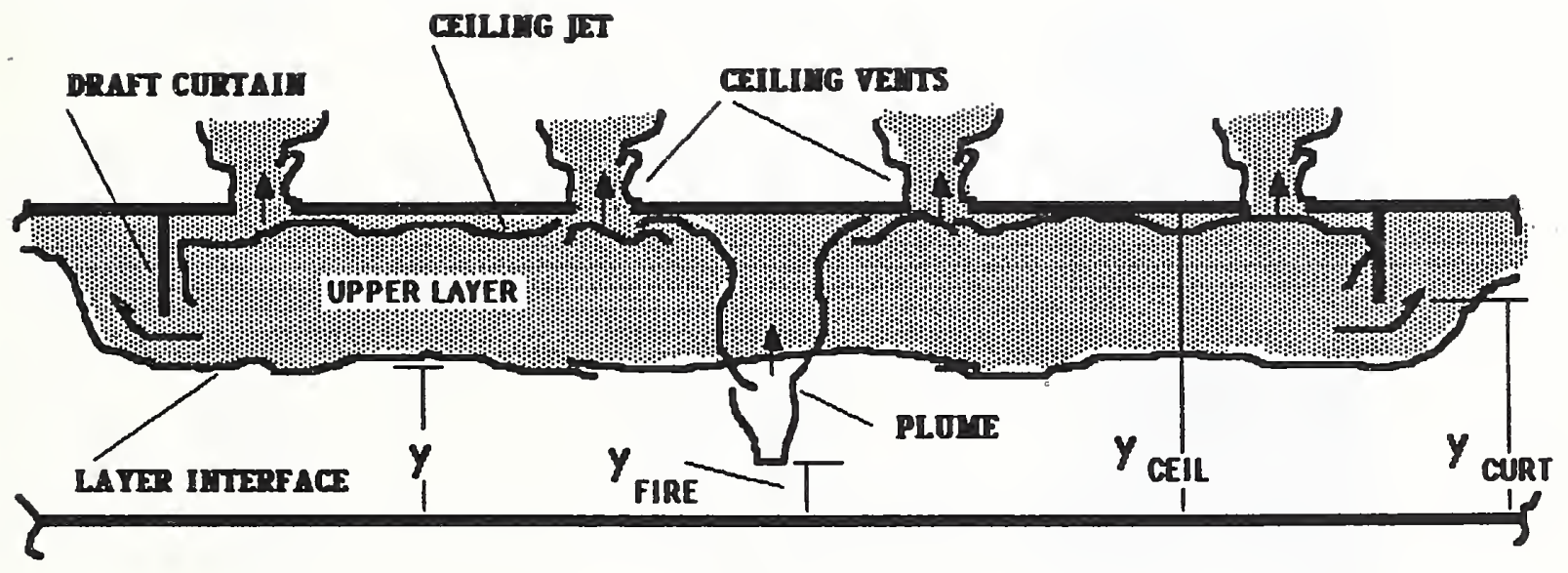

Figure 1. Fire in a building space with draft curtains and ceiling vents 


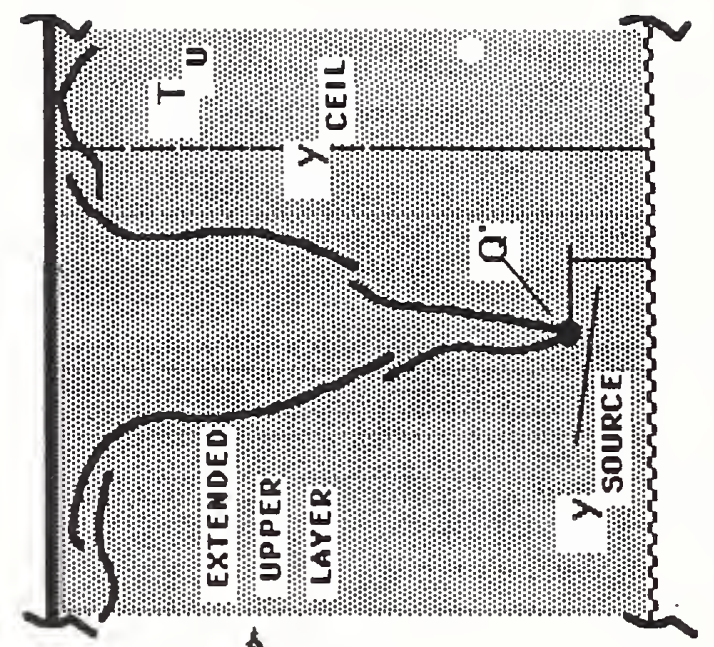

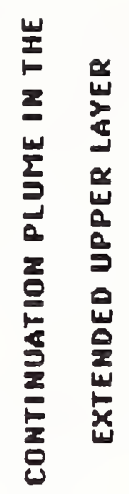

迆

뭉

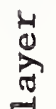

40

弪

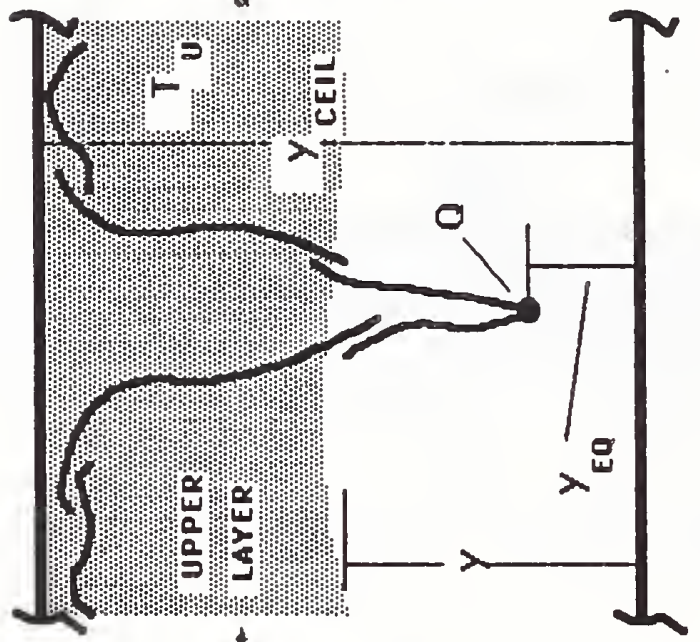

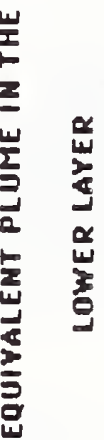

림

$\leftarrow \frac{2}{5}$

ปั

है

尔

일

F

站

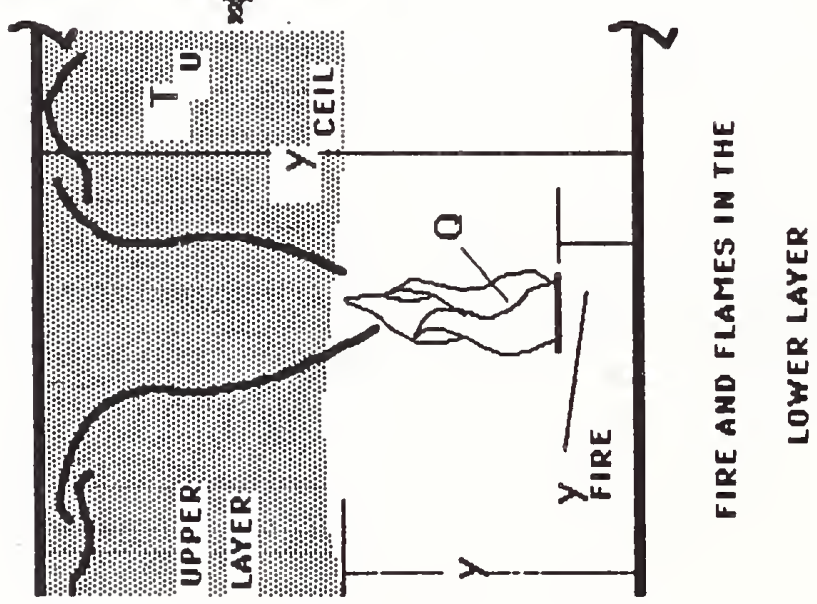

동

ช

许

E리

$\dot{\sim}$

빙

: 


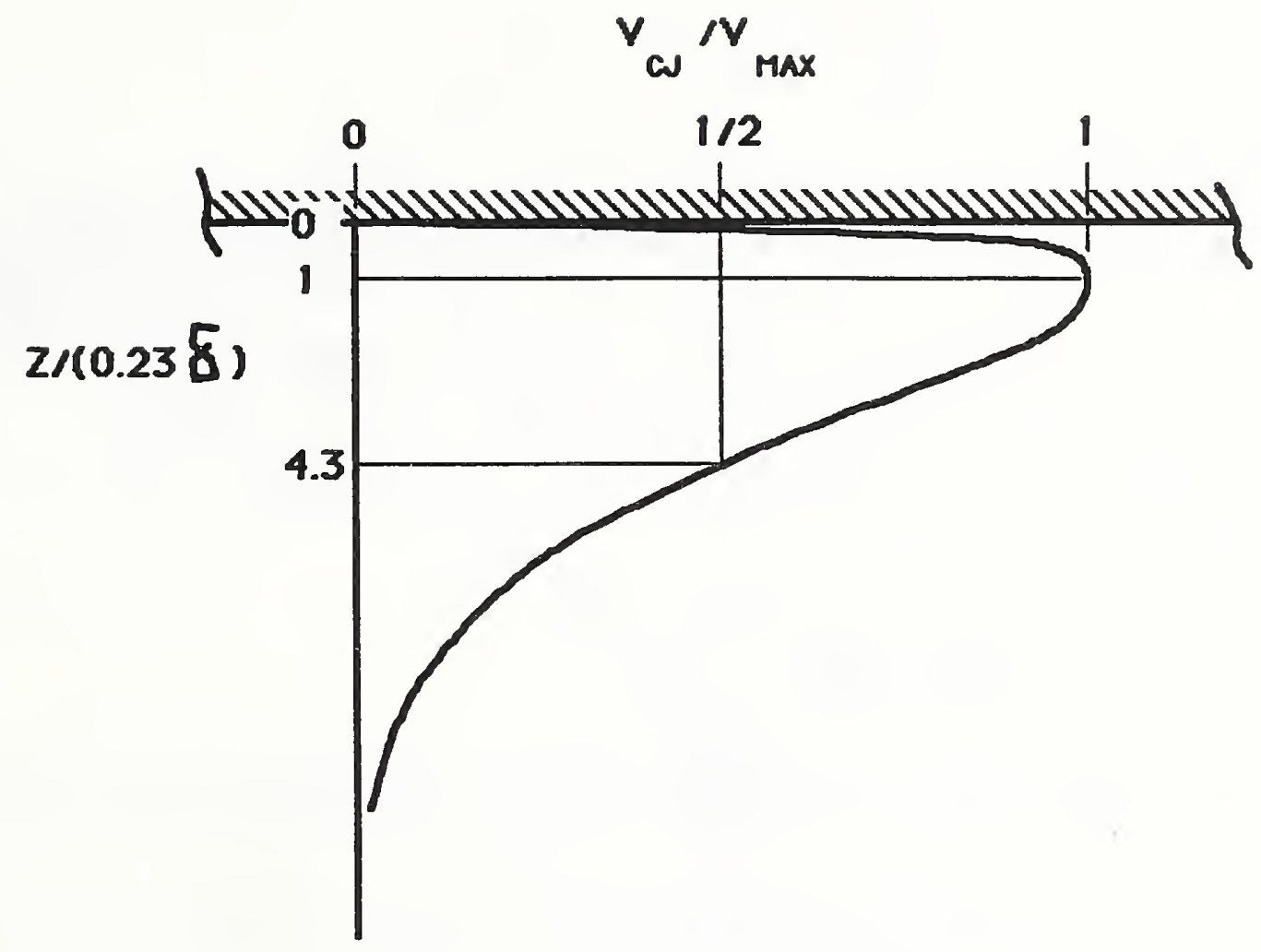

Figure 3. A plot of dimensionless ceiling jet velocity distribution, $v_{C J} / V_{\text {MAX }}$, as a function of $z /(0.23 \delta)$ per Eq. (49) 


$$
\theta=\left(T_{\omega}-T_{u}\right) /\left(T_{\max }-T_{u}\right)
$$

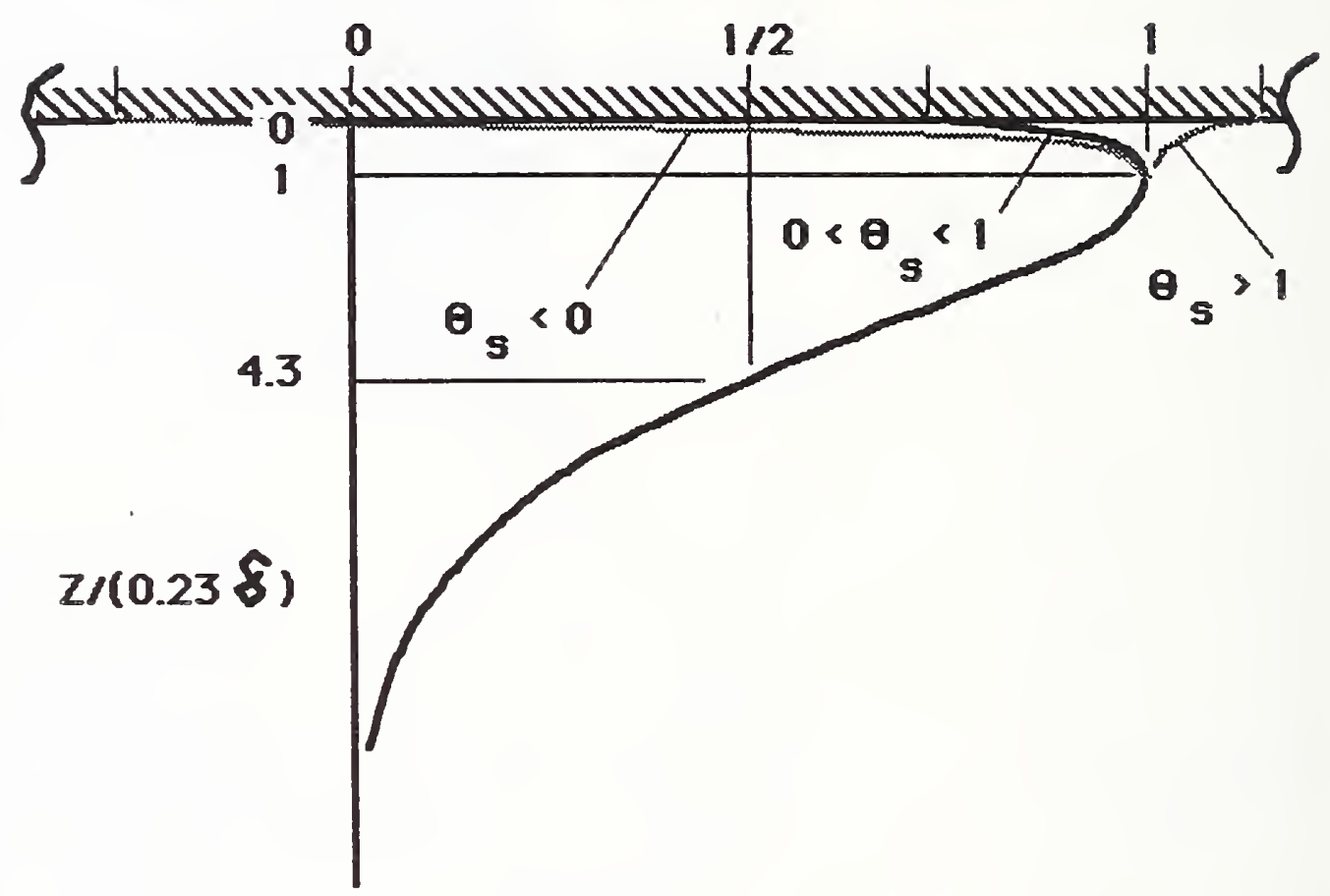

Figure 4. Plots of dimensionless ceiling jet temperature distribution, $\theta$, as a function of $z /(0.23 \delta)$ per Eq. (52) for cases when $\theta_{S}$ is $<0$, between 0 and 1 , and $>0$ 


\begin{tabular}{|c|c|c|c|}
\hline $\begin{array}{l}\text { O.STEPT. OF COMM. } \\
\text { BIBLIOGRAPHIC DATA } \\
\text { SHEET (See in structions) }\end{array}$ & $\begin{array}{l}\text { 1. PUBLICATION OR } \\
\text { RFPORT NO. } \\
\text { NBSIR } 88-3734\end{array}$ & 2. Performing Organ. Report Nof & $\begin{array}{r}\text { 3. Publication Date } \\
\text { April } \perp 988\end{array}$ \\
\hline
\end{tabular}

\section{TITLE AND SUBTITLE}

Estimating the Environment and the Response of Sprinkler Links in Curtained Compartment Fires with Fusible Link-Actuated Ceiling Vents - Part I: Theory

\section{AUTHOR(S)}

Leonard Y. Cooper

6. PERFORMING ORGANIZATION (If joint or other then NBS, see instructions)

NATIONAL BUREAU OF STANDARDS

U.S. DEPARTMENT OF COMMERCE GAITHERSBURG, MD 20899

9. SPONSORING ORGANIZATION NAME AND COMPLETE ADDRESS (Street, City, State, ZIP)

AAMA Research Foundation

2700 River Road, Suite 118

Des Plaines, Illinois 60018

10. SUPPLEMENTARY NOTES

Document describes a computer program; SF-185, FIPS Software Summary, is attached.

11. ABSTRACT (A 200-word or less foctual summary of most significant information. If document includes a significant bibliography or literature survey, mention it here)

The physical basis and associated mathematical model for estimating the firegenerated environment and the response of sprinkler links in well-ventilated, curtained compartment fires with fusible link-actuated ceiling vents is developed. Complete equations and assumptions are presented. Phenomena taken into account include: the flow dynamics of the upward-driven, buoyant fire plume; growth of the elevated-temperature smoke layer in the curtained compartment; the flow of smoke from the layer to the outside though open ceiling vents; the flow of smoke below curtain partitions to building spaces adjacent to the curtained space of fire origin; continuation of the fire plume in the upper layer; heat transfer to the ceiling surface and the thermal response of the ceiling as a function of radial distance form the point of plume-ceiling impingement; the velocity and temperature distribution of plumedriven near-ceiling flows and the response of near-ceiling-deployed fusible links as functions of distance below the ceiling and istance from plumeceiling impingement.

The theory presented here is the basis of a computer model now under development which will be used to study parametrically a wide range of relevant fire scenarios. The results of the parametric study will be presented in the Part II: Application portion of this paper.

12. KEY WORDS (Six to twelve entries: alphabetical order: capitalize only proper names: and separate key words by semicolons) algorithms; building fires; compartment fires; computer models; fire models; mathematical models; vents; sprinkler response: zone models

\section{AVAILABILITY}

[X] Unlimited

$\square$ For Official Distribution. Do Not Release to NTIS

$\square$ Order From Superintendent of Documents, U.S. Government Printing Office, Washington, D.C. 20402.

Order From National Technical Information Service (NTIS), Springfield, VA. 22161

14. NO. OF

PRINTED PAGES 37

15. Price

$\$ 11.95$ 

